\title{
Arbor
}

\section{«Una reflexión serena y objetiva». Galileo y el intento de autorre- habilitación de la Iglesia Católica}

\section{Antonio Beltrán}

Arbor CLX, 629 (Mayo 1998), 69-108 pp.

En 1979, el papa Juan Pablo II ordenaba una "reflexión serena y objetiva» sobre el caso Galileo. Posteriormente el pontífice ha reiterado el impulso y el respeto de la Iglesia a la libertad de la investigación y a la legítima autonomía de la ciencia. Aquí se examinan dos ejemplos de estas directrices y actitudes de la Iglesia. El primero es la interpretación de las condenas de Copérnico y Galileo que empezó a gestarse, tras la muerte de este último, en el seno de la Iglesia católica, y que hoy tiene su última versión en W. Brandmüller, uno de los miembros de la comisión papal para el estudio del caso Galileo, interpretación que diluye la gravedad de las condenas de 1616 y 1633 y atribuye a la Iglesia un escrúpulo científico que Galileo no habría tenido. El segundo ejemplo examinado es el "caso Paschini»: la censura y manipulación de su texto sobre Galileo por parte de las autoridades del Vaticano que se lo habian encargado.

En octubre de 1936, el Vaticano era una fiesta. El Papa Pío Xl, en un apasionado discurso repetía una vez más las tesis que se venían oyendo desde hacía siglos y que el concilio Vaticano I había hecho suyas. 
«la fe y la razón no sólo no pueden contradecirse jamás entre sí, sino que más bien se ofrecen ayuda mutua...." ${ }^{1}$

Pero Pío XI lo formula con esa llamémosla "osadía", típica de los papas.

«La ciencia, entendida como conocimiento verdadero de las cosas, no contradice nunca las verdades de la fe cristiana; antes al contrario -como tiene que admitir cualquiera que examine y medite la historia de la ciencia-, mientras que, por una parte, los romanos pontífices en ninguna época han dejado de favorecer las investigaciones de los hombres doctos, incluso en el campo de las ciencias experimentales, éstas, a su vez, han dado una valiosa contribución a la defensa del tesoro celeste, confiado a la propia Iglesia».

Naturalmente, no sólo es falso que los papas y la Iglesia siempre hayan favorecido la investigación científica, sino que en muchas ocasiones sucedió exactamente lo contrario, como todo el mundo sabe. El caso de las condenas del copernicanismo y de Galileo, de las que nos ocuparemos aquí, no son sino dos de los más clamorosos. Pero el Papa debía estar profundamente emocionado porque, como comenta a continuación

«ha sucedido, en los últimos tiempos, que algunos científicos, que primero habían habitado en la casa paterna de la hereditaria religión, en alguna ocasión la abandonaron míseramente - si bien, de hecho, no para aprender la verdad-.

e incluso se había dicho, sobre todo en el s. XIX, que ciencia y fe se oponen. Pero, añadía el Santo Padre,

«Pero ahora tales prejuicios - como se puede constatar con no poco consuelo - han caído en tal descrédito que apenas se encuentra a alguien, entre los que se ocupan dignamente de la investigación física, que se haga asertor y campeón de este error" ${ }^{2}$.

Más aún, el Papa, entusiasmado, afirma que no quiere silenciar el hecho de que, durante su pontificado, muchos de los científicos, a veces los mejores de su especialidad, que han acudido a Roma para distintos congresos,

«se han presentado a Nos, ofreciendo su reverente homenaje a Nos mismo, o más bien a la autoridad que, en la persona del Sucesor, 
«Una reflexión serena y objetiva». Galileo y el...

aunque sea inmerecida, del Beato Pedro, ha sido confiada a perpetuidad a esta apostólica sede».

Pero eso no era todo.

"Sucedió además, que entre estos personajes los hubo que, aun no teniendo el don preciosísimo de la fe católica, sin embargo creyeron razonable inclinar reverentes su frente ante esta Nuestra Cátedra de verdad.

Y no faltaron los que, hablándonos en nombre de sus colegas, no dudaron en declarar, con justa razón, que la ciencia, en cualquiera de sus ramas, abre y consolida el camino que conduce a la fe cristiana. Y el oír esto fue, de verdad, motivo de gran alegría para Nuestro ánimo paterno". ${ }^{3}$

No resulta extraño, pues, que el Santo Padre, embelesado ya, declarara:

"Guiado, pues, por tal entendimiento, Nos, desde la plenitud de Nuestra Potestad, 'motu propio' y después de Nuestra madura deliberación... declaramos instituida la "Academia Pontificia de Ciencias"» 4 .

Estamos, sin duda, ante un buen ejemplo de lo que la Iglesia católica entiende por diálogo entre Papa y científicos, entre Iglesia y comunidad científica, entre fe y ciencia. Aunque hay que reconocer que la alternativa entre ser un miserable que se encamina al error o inclinarse reverente ante alguien que se considera y se denomina a sí mismo "Nuestra cátedra de verdad" no parece la mejor descripción de un diálogo.

Resulta por lo menos irónico que la Academia Pontificia de Ciencias se reclamara continuadora de la Accademia dei Lincei que Federico Cesi había fundado en 1603 y de la que Galileo había sido el más insigne miembro. La Accademia dei Lincei, especialmente desde que Galileo ingresó en ella, reunió un núcleo de personajes que se mostraban partidarios de la renovación de la cultura del momento y, en ella, se publicó Il Saggiatore de Galileo que, entre otras cosas, constituye una contundente crítica a la filosofĩa y política cultural dominantes, basadas en el principio de autoridad. Pero ya sabemos que, con el triunfo de las fuerzas más radicales de la Contrarreforma, aquella propuesta de innovación fracasó. Con la muerte del Príncipe Cesi en 1630, la Accademia dei Lincei y su patrimonio entró en proceso de liquidación. La biblioteca fue puesta a la venta, no antes de que el Maestro del Sacro Palazzo secuestrara una serie de obras y manuscritos, cuyos 
títulos desconocemos ${ }^{5}$. En estos momentos, los problemas de Galileo con la Iglesia estaban entrando en su fase más aguda.

Pero ahora, en el s. XX, la Iglesia, que con la condena de Galileo precisamente había acabado drásticamente con aquella renovadora propuesta cultural linceana, decidía presentarse, como puede verse, como su meritoria continuadora. El papa Pío IX ya había instituido lo que se denominaría Pontificia Accademia dei Nuovi Lincei. Y tras distintos avatares, el entusiasta Pío XI la reorganizó, como acabamos de ver, dándole el nombre actual.

La política cultural de esta institución está muy lejos del espíritu que inspiró a aquellos primeros linceos. Pero no puede decirse que no se hayan interesado por Galileo. El papa Juan Pablo II, en 1979, eligió precisamente esta institución para hacer el famoso discurso con el que ponía en marcha lo que se conoce comúnmente como "rehabilitación Galileo", una operación que, en realidad, como podrá deducirse de lo que sigue, se planteó desde un principio como una autopromoción y autorrehabilitación por parte de la Iglesia católica ${ }^{6}$. Para «la reflexión serena y objetiva» ${ }^{7}$ sobre el caso Galileo, Juan Pablo II encargó «a un grupo de personalidades cualificadas" la formación de una comisión que se constituyó en cuatro secciones ${ }^{8}$. Éstas publicaron sus respectivos trabajos, y a partir de ellos, el Papa Juan Pablo II, concluyó en 1992 que, frente a la imagen de "Galileo como símbolo del supuesto rechazo del progreso científico por parte de la Iglesia", y a «la idea de que existe incompatibilidad entre el espíritu de la ciencia y su ética de la investigación, por un lado, y la fe cristiana por otro".

"Las aclaraciones aportadas por los estudios históricos recientes nos permiten afirmar que este doloroso malentendido pertenece al pasado" ${ }^{9}$.

Del estudio de todo este asunto más bien se desprende la conclusión contraria. Ya he aludido en otro lugar a algunos aspectos centrales de la cuestión y a uno de estos estudios históricos, resultante del trabajo de la sección cultural de la comisión papal para el caso Galileo ${ }^{10}$. Aquí, al hilo de un repaso de algunos puntos importantes en la evolución del "caso Galileo" desde la muerte de éste hasta hoy, podremos ver cómo algunos de «estos estudios históricos recientes" a los que alude el Papa, constituyen la más clara prolongación del problema. Especialmente relevante en este sentido es la edición de las actas del Santo Oficio en las que se da cuenta de la larga discusión que, entre 1820 y 1823, precedí a la retirada de las obras copernicanas del Indice de libros prohibidos, que se concretaría muchos años después. La edición 
«Una reflexión serena y objetiva». Galileo y el...

de estos importantes documentos, auspiciada por la Academia Pontificia de Ciencias, fue encargada a los profesores Walter Brandmüller y Egon J. Greipl ${ }^{11}$. En una larga introducción Brandmüller presenta una reconstrucción de los avatares de la condena de Galileo y las interpretaciones que de ella se hicieron, desde la muerte de Galileo hasta 1820, que hace que el propio Brandmüller, y la Academia Pontificia de Ciencias que le apadrina, se conviertan a su vez en parte protagonista del tema a estudiar. En efecto, Brandmüller aparece como el último eslabón de una interpretación de las condenas de la teoría copernicana 1616 y de Galileo en 1633 que la Iglesia empezó a gestar apenas Galileo acababa de morir. Pero, para poder hacernos idea del valor de sus tesis, y de su catadura moral e intelectual, es preciso dar una mínima información respecto de la condena del copernicanismo en 1616 y de la condena de Galileo en 1633. Veámoslo brevemente.

Tras las denuncias hechas contra Galileo, el 24 de febrero de 1616 fueron presentadas a la Congregación del Santo Oficio dos proposiciones para ser censuradas. Cito textualmente del acta:

«1. El sol es el centro del mundo y totalmente inmóvil de movimiento local.

Censura: Todos dijeron que esta proposición es necia y absurda en filosofía y formalmente herética, puesto que contradice explícitamente numerosas afirmaciones de las Sagradas Escrituras en su sentido literal y según el sentido y la interpretación común que hacen los Santos Padres y los doctores en teología".

2. La Tierra no es el centro del mundo ni está inmóvil, sino que se mueve como un todo (secundum se totam) y también con movimiento diurno.

Censura: Todos dijeron que esta proposición merece la misma censura que la anterior en filosofía, y en cuanto a la verdad teológica es cuanto menos errónea con respecto a la fe» ${ }^{12}$ (cursiva mía).

A raíz de este acuerdo, el Papa ordenó a Bellarmino que notificase a Galileo, ante el Padre Comisario del Santo Oficio, que debía abandonar estas opiniones; si se negaba el Padre Comisario debía ordenarle, ante notario y testigos, que se abstuviese totalmente de enseñar, defender o incluso tratar de cualquier modo esta doctrina y opinión; y. si se negaba debía ser encarcelado. La documentación en este punto plantea muchos problemas. No sabemos qué paso exactamente en el acto de 
notificación. Existe un documento sin firma ninguna según el cual el Comisario del Santo Oficio le dio a Galileo las tres ordenes que sólo debían darse sucesivamente en caso de negativa. No se trata de un original, pero no es fácil decidir si este documento es una mera falsificación o qué carácter tiene. Existe además una carta de Bellarmino que entra en contradicción con dicho documento en puntos importantes. En todo caso, el 5 de marzo de 1616 se publicó el Decreto de prohibición del copernicanismo. En éste se dice que la Congregación del Indice ha sabido que

la difusión y aceptación por muchos de la doctrina pitagórica, falsa y además totalmente contraria a la Sagrada Escritura, de que la tierra se mueve y el Sol está inmóvil, que sin embargo es defendida por el De Revolutionibus Orbium Coelestium de Copérnico... la Congregación determina que

1) Quedan suspendidos hasta que sean corregidos el De Revolutionibus de Copérnico y el Comentario sobre el libro de Job de Diego de Zúñiga.

2) El libro de Foscarini queda "completamente prohibido y condenado"

3) Son igualmente prohibidos «todos los demás libros que enseñen lo mismon ${ }^{13}$.

La diferencia de las condenas de unos textos y otros pone de manifiesto que la teoría copernicana era condenada como falsa y herética, pero que podía tratarse como una hipótesis, un término de enorme ambigüedad que ninguno de los protagonistas parecía interesado en clarificar ${ }^{14}$. La obra de Copérnico se suspendía hasta que se corrigiera. Pero la de Foscarini se condenaba sin más porque sostenía la compatibilidad de la doctrina con las Escrituras.

En 1624 Urbano VIII había dado permiso a Galileo para escribir una obra sobre cosmología a condición de que la teoría copernicana fuera tratada como mera hipótesis matemática, además de alguna otra condición. Galileo reitera al principio, al final y a lo largo del texto, en numerosas ocasiones, que considera la teoría copernicana como una mera hipótesis matemática y que él sólo se "disfraza" de copernicano pero que en realidad no se aparta de las directrices de la Iglesia. No es menos cierto que a lo largo de la argumentación la teoría geocéntrica tradicional aparece como una antigualla obsoleta, mientras que la copernicana parece claramente superior y no sólo como mera hipótesis matemática. Ahora bien, la propia Iglesia había desa- 
rrollado una larga, compleja y enrevesada tradición en la que tesis consideradas filosófica y teológicamente erróneas eran sólidamente defendidas a lo largo de numerosas páginas, cuyos argumentos se neutralizaban al final con una mera adhesión a la ortodoxia. El caso de Nicolás de Oresme es bien significativo. Desbarata todos los argumentos clásicos, basados en la experiencia, en la filosofía aristotélica y en la Biblia, contra el movimiento terrestre, y al final hace una escueta declaración de fe en la teoría geocéntrica, por fidelidad a la Biblia y a la autoridad de la fe católica ${ }^{15}$. No se le consideró un falsario, a pesar de que su texto, formalmente, es incluso más desequilibrado que el de Galileo.

Está claro que las numerosas declaraciones explícitas de Galileo respecto al carácter puramente hipotético/matemático de la teoría copernicana y en el sentido de que su copernicanismo era sólo fingido, permitían afirmar que había obedecido el mandato del Papa. Decidir si tales declaraciones debían considerarse suficientes y plenamente satisfactorias dependía sólo del humor del Papa. Y cuando se publicó el Dialogo en 1630, Urbano VIII tenía un humor de perros. Todos sus proyectos políticos se venían abajo y sus enemigos, ayudados por los jesuitas, le ganaban la partida.

El hecho es que en 1632 se acusó a Galileo de haber desobedecido la admonición de 1616 en la que se le prohibía tratar la teoría copernicana quovismodo, es decir ni como hipótesis matemática ni como teoría física verdadera. Galileo no acepta la acusación y, cuando esgrime el certificado que le redactó Bellarmino, la base de la acusación se viene abajo. En un segundo momento, y tras oscuros e irregulares procedimientos, se le acusa de que en el Diálogo defiende la teoría copernicana como verdadera. Aunque se había establecido que la Congregación debía estar al completo, la sentencia sólo fue leída y firmada por siete de los diez cardenales. Los otros tres ni siquiera participaron en la sesión. No sabemos la causa.

Destaquemos que la sentencia hace historia de la cuestión y recoge literalmente el dictamen de la Congregación del Santo Oficio en 1616, en la que se califica el heliocentrismo y helioestatismo como proposición "formalmente herética" y la del movimiento terrestre como «errónea con respecto a la fe».

Al final, establece una doble acusación:

«Decimos, pronunciamos, sentenciamos y declaramos que tú, Galileo, ...te has hecho ante este Santo Oficio vehementemente sospechoso de herejía, 


\section{Antonio Beltrán}

1) esto es, de haber sostenido y creído una doctrina falsa y contraria a las Sagradas Escrituras, es decir que el Sol es e! centro del mundo y no gira de oriente a occidente, y que la Tierra se mueve y no está en el centro del mundo,

2) y que se puede sostener y defender como probable una opinión después de que ésta haya sido declarada y definida como contraria a la Sagrada Escritura. (Opere XIX, pp. 402-407; Finocchiaro p. 291)

Cabe aclarar que el "vehementemente" y el "sospechoso" de la fórmula "vehementemente sospechoso de herejía" no refieren ni un estado psicológico ni una creencia que pudiera resultar falsa, sino que constituyen una expresión técnica. Al igual que la fórmula utilizada en 1616, "formalmente herético", indican gradaciones de la gravedad del ataque a la fe. $\mathrm{El}$ "hereje en sentido estricto" es el que comete "herejía formal» que es la más grave. Después existe una amplísima casuística que incluye al "sospechoso de herejía" que, a su vez, tiene distintas categorías: sospechoso "leve", "vehemente" y "violento" en un grado creciente de gravedad ${ }^{16}$.

El 23 de Agosto de 1634 se publicó un Decreto de prohibición del Diálogo de Galileo que, desde entonces aparece en el Indice de los libros prohibidos.

La condena de Galileo y de la teoría copernicana no sólo fue una tragedia personal. En Italia, donde la Iglesia tenía un mayor control, la ciencia sufrió una progresiva decadencia. En el extranjero no sucedió lo mismo, pero existía una clara preocupación. Los copernicanos, si querían seguir siéndolo, tenían que buscar alguna sutileza o subterfugio que les diera alguna posibilidad o esperanza. Un buen ejemplo lo tenemos en Descartes. Apenas se entera de la condena de Galileo, le escribe a Mersenne, en enero de 1634:

"Puesto que aún no he visto que ni el Papa ni el Concilio hayan ratificado esta condena, hecha solamente por la congregación de los cardenales, constituida para la censura de los libros, me gustaría saber... si su autoridad ha sido suficiente para hacer de ella un artículo de fe" ${ }^{17}$.

Ante todo, aclaremos un posible equívoco. Estamos ante un elemento formal. No se trata, ni nadie lo ha insinuado jamás, de que el Papa Urbano VIII no aprobara la condena y la sentencia. No hay ninguna duda de que incluso la instigó y se mostró más inflexible que nadie tanto durante el juicio como después de la condena. Pero ese carácter formal no obsta para que, desde un punto de vista jurídico, pudiera 
«Una reflexión serena y objetiva». Galileo y el...

ser importante. En efecto, la posibilidad del subterfugio es clara. Pero es igualmente claro que sólo puede usarse desde la propia Iglesia, porque, en realidad, que tal posibilidad progrese no depende tanto de su valor legal, como de la libre voluntad del Papa. Más aún, el propio Galileo había aludido ya a estas sutilezas antes de la condena de $1616 y$, como es bien sabido no sirvió de nada. En efecto, en su Carta a Cristina de Lorena ya había esgrimido el requisito legal. Al aludir a los que se han refugiado en las Escrituras para ocultar su incapacidad científica, comenta, con más temor que convicción que «no es competencia suya ni de los otros, sino del Sumo Pontífice o de los sagrados concilios el declarar una proposición como errónea" ${ }^{18}$. Naturalmente, cuando una año más tarde, en 1616, cuando la Congregación del Indice publicó el Decreto de condena del copernicanismo, ni a Galileo ni a nadie se le ocurrí que ahora había que esperar que el Papa o un concilio se pronunciara al respecto ${ }^{19}$. Ahora, tras la condena, cuando Galileo quiere contrarrestar la dureza de los informes de Gucciardini, embajador de la casa Medici en Roma, acude a otras sutilezas. Dice que su enemigo y denunciante el dominico Caccini quería convencer a todos de que la teoría copernicana era "contraria a la fe y herética", pero que "su parecer no ha hallado eco en la Santa Iglesia, la cual sólo ha decidido que tal opinión no concuerda con las Escrituras" ${ }^{20}$. Pero, naturalmente, sabe que ha fracasado totalmente en su campaña copernicana, que él se ha salvado por los pelos, y que ningún distingo formalista puede aliviar la tragedia. También el Papa le trata amabilísimamente y le asegura que mientras él viva, Galileo podrá sentirse seguro y a salvo de los calumniadores. Pero ha sido este mismo Papa el que días antes ha ordenado a Bellarmino que amonestara y amenazara a Galileo si no abandonaba la teoría copernicana ${ }^{21}$. Son formalismos de corte que no modifican en absoluto lo dramático de la situación.

Pues bien, también Descartes sabe que de facto no hay ninguna diferencia entre la prohibición de la Congregación de la Inquisición o del Indice y la del Papa. Sabe perfectamente que una cosa son las sutilezas jurídicas y otra muy distinta la realidad. Y su actitud queda muy clara en una carta a Mersenne dos meses posterior. El 10 de Abril de 1634, le comenta que sus propias teorías del tratado El Mundo se basaban en la teoría copernicana, pero que por más indudables que fuesen sus demostraciones

«no querría por nada del mundo defenderlas contra la autoridad de la Iglesia. Sé que se podría decir que todo lo que han decidido los inquisidores de Roma no es por ello artículo de fe incontinenti, y que 
antes es necesaria la aprobación del concilio. Pero no estoy tan enamorado de mis ideas como para querer servirme de tales salvedades para tener un modo de mantenerlas" 22 .

Descartes tenía miedo, claro está. ¿Y quién no, ante la Inquisición? ¿Quién se atrevía a defender el copernicanismo al amparo de este distingo legalista? En aquellos momentos nadie. Ni siquiera los copernicanos como Descartes que lo esgrimían como una remota esperanza. Pero estaba claro que era una posibilidad abierta, y tenía un gran porvenir. De hecho, sería el punto central que utilizaría la Iglesia católica para dar un nuevo sentido a las condenas de 1616 y 1633.

Ya en 1615 Galileo había advertido la difícil situación que se plantearía si se declaraba herética la teoría del movimiento terrestre y después iban apareciendo observaciones y demostraciones que mostraban dicho movimiento ${ }^{23}$. Siendo generosos, podemos decir que, a finales del s. XVII, con la obra de Newton, quedó definitivamente aceptada, en la comunidad científica y en el mundo culto en general, una cosmología "copernicana" que incluia las dos proposiciones condenadas como heréticas. ¿Qué hizo la Iglesia a partir de entonces? Desarrollar las posibilidades de las sutilezas legales que, con propósito muy diferente, habían planteado algunos copernicanos como Descartes, $\mathrm{y}$ atribuirles una imporiancia que no tuvieron en absoluto.

Es muy signifizativo que, desde un principio, los grandes campeones de esta línea argumentativa fueran los jesuitas. El primero que afronta claramente la cuestión es Gian Battista Riccioli, en su Almagestum Novum de 1651. Señalaba que sólo el Papa o un Concilio presidido por él tienen autoridad para definir un principio de fe, pero no así las congregaciones cardenalicias. En consecuencia, afirmaba literalmente que

«Aún no es de fe que el Sol se mueve y la Tierra está quieta; sino a lo sumo y sólo en virtud de las Sagradas Escrituras para aquellos que es moralmente cierto que Dios lo ha revelado así. Sin embargo, todos nosotros, los católicos, por deber de prudencia y de obediencia, estamos obligados a sostener lo que aquella Congregación estableció, o al menos a no enseñar en forma absoluta lo contrario" ${ }^{24}$.

Debemos recordar que esto se decía en una obra, el Almagestum Novum, que, a pesar de la admiración expresada por Copérnico, se inclinaba por una versión modificada del sistema geoheliocentrista de Tycho Brahe. Era una obra que se presentaba como una justificación científica de la sentencia contra Galileo. Y este argumento era la con- 
«Una reflexión serena y objetiva». Galileo y el...

trapartida jurídica de la justificación. Así pues, la diferencia con Descartes es obvia, por más que suelan presentarse todos los que han esgrimido el distingo jurídico como participando en una misma línea de desarrollo argumental ${ }^{25}$. Como he dicho, Descartes pretendía evitar la condena y deseaba su anulación, no justificarla científicamente y salvarla jurídicamente, como Riccioli. Y, sobre todo, Descartes tenía miedo, pero no mala conciencia ${ }^{26}$. Por eso es más llamativo el comentario de Brandmüller:

"Con esta toma de posición, Riccioli había puesto de manifiesto su apertura hacia Copérnico y Galileo, sin renunciar por lo demás al carácter hipotético de sus teorías. No se trataba de doblez y menos aún de una manifestación de hipócrita conformismo sino de una conciencia de los problemas científico-teóricos, acentuada por una formación filosofico-teológica” ${ }^{27}$.

Brandmüller sabe muy bien que, en su orden, los jesuitas habían institucionalizado la doblez y el conformismo hipócrita. "En pro de cosas más importantes", naturalmente. Obviamente no estoy haciendo una mera apreciación personal. La documentación al respecto, publicada hace unos años por Baldini ${ }^{28}$, es clara e inequívoca y Brandmüller la conoce aunque no la usa.

Desde un principio, conocemos cartas como las de Nicolás Peiresc o de algunos jesuitas que dejan muy claro que algunos de los matemáticos jesuitas no consideraban condenable la teoría copernicana y que unos pocos incluso no estaban muy lejos de ella ${ }^{29}$.

Pues bien, hoy, gracias a Ugo Baldini, como decía, conocemos con detalle los mecanismos y las directrices de la censura interna de la 'Compañía de Jesús. Sabemos que unos pocos matemáticos jesuitas hubieran visto con buenos ojos una cierta aproximación a las nuevas teorías. Pero nos consta documentalmente que la obediencia, máximo valor de la Compañía de Jesús, se impuso a la ciencia. En especial, después de la condena de 1616, cerraron filas sin la más mínima fisura. Sabemos hoy que algunos jesuitas que, en privado, no se mostraban contrarios al copernicanismo publicaban obras que, tras ser debidamente censuradas por la Compañía, aparecían como claramente antigalileanas o anticopernicanas. Algunos, como Scheiner, lo hacían con pasión. Otros, como Biancani, parecen haber obedecido de buen grado, pero sin el mismo entusiasmo ${ }^{30}$. Así pues, en especial tratándose del copernicanismo galileano, eso que Brandmüller denomina «doblez e hipócrita conformismo" era la política oficial que la orden jesuita 
imponía a los muy escasos miembros de la orden que tenían alguna tendencia hacia la teoría copernicana.

Pero el legalismo de Riccioli tuvo un creciente éxito y desarrollo. En 1678, otro jesuita, Antonio Baldigiani daba un pasito más. El suficiente para pasar directamente a la más burda falsedad:

«no se condena a Galileo por sus doctrinas, ni se dice siquiera que haya herejía contra la Escritura, de dudosa fe, sino que sólo se discute sobre el modo en que escribió, que es una cuestion muy distinta de la primera" ${ }^{31}$.

Está claro que los hechos y los documentos importan cada vez menos. Unos años más tarde, en 1685, otro jesuita, cómo no, Adam Kochánsky afirmaba que era lícito buscar pruebas de la teoría copernicana y que, en caso de hallarlas, los textos de la Escritura podrían explicarse adecuadamente.

Recordemos una vez más que la segunda herejía explícitamente mencionada en la sentencia de Galileo consistía en que éste había afirmado «que se puede sostener y defender como probable una opinión después de que ésta haya sido declarada y definida como contraria a la Sagrada Escritura". Eso era condenado como herético.

No obstante, Brandmüller se precipita a afirmar:

"Así, -es decir, con las tesis de Riccioli y Baldigiani-quedaba eliminado además cualquier obstáculo teológico-bíblico a la investigacion” ${ }^{32}$.

El entusiasmo apologético de Brandmüller es conmovedor. Acepta entusiasta el argumento de Riccioli: la condena del copernicanismo no es materia de fe porque la hizo la Inquisición y no el Papa o un concilio. Pero no parece darse cuenta de que, una vez aceptado el argumento de la jerarquía, implica una clara contradicción el afirmar que lo que dice un oscuro matemático pueda estar por encima de una sentencia firme de la Inquisición y anular su valor y consecuencias. Pero veremos que, en otros momentos de su historia, compensará con creces al Santo Tribunal de este desliz, fruto, por lo demás, de las mejores intenciones.

En 1710 y en 1740 se publicaron, con licencia eclesiástica, sendas ediciones del prohibido Diálogo de Galileo, aunque ambas adjuntaban el texto de la sentencia de 1633 y la abjuración. Comentando la edición de 1710 , Brandmüller dice que

$$
\text { "quedaba así resuelta "vía facti" la cuestión Galileo" }{ }^{33} \text {. }
$$


«Una reflexión serena y objetiva». Galileo y el...

Desafortunadamente, a pesar de que el caso Galileo quedaba resuelto una y otra vez, éste seguía condenado y su obra en el Indice, como es palmario. Y seguía vigente a pesar de que en 1734 James Bradley, con su descubrimiento de la aberración de la luz estelar, había aportado ya una prueba físico-astronómica del movimiento terrestre. Brandmüller alude, obviamente como un mérito de la Iglesia, a que la difusión de este descubrimiento no tuvo ninguna dificultad en Italia. Más aún, nos informa además de que, en aquellos momentos, todavía los había que rechazaban el sistema heliocéntrico; y de que, incluso después de 1742 , «se dejaban oír objeciones al heliocentrismo de Galileo" ${ }^{34}$. Desafortunadamente, no nos dice cuáles eran esas objeciones del filósofo, pedagogo, sacerdote y teólogo Gregorio Bressani.

En 1757 la Congregación del Indice decide que, en su edición de 1758, éste ya no incluiría el Decreto de 1616 que prohibía las obras que sustentaran la teoría heliocéntrica. Brandmüller es deliberadamente oscuro en este punto. Pero debe quedar claro que esta exclusión del Decreto no implicó que las obras copernicanas condenadas, Copérnico y Galileo incluidos, se eliminaran del Indice. Por el contrario, las obras de Copérnico y Galileo no fueron eliminadas del Indice hasta casi un siglo después, como veremos 35 . No obstante, para Brandmüller, otra vez el problema resuelto.

"Después de esta intencionada y clara decisión, el heliocentrismo, para los científicos romanos, ya no constituía un problema" ${ }^{36}$.

En esta misma línea, D'Addio nos informa de que el jesuita Luigi Brenna, autor de una biografia de Galileo publicada en 1778

«había observado que, tras los numerosos descubrimientos científicos, la teoría copernicana-galileana es ahora universalmente postulada, sin que las autoridades eclesiásticas intervinieran para hacer valer la antigua condena y para impedir la difusión de las obras pertinentes" ${ }^{37}$.

Lo más curioso es que Brenna - no me atrevo a afirmar que también es la postura de D'Addio- lo menciona, obviamente, como un elemento positivo en favor de la Iglesia, no como una contradicción, o al menos confusión, flagrante. Por no mencionar el hecho evidente de que, en estos tiempos, y aunque hubiera querido, la Iglesia simplemente no tenía poder suficiente para imponer al mundo culto sus sentencias antiguas o modernas. La pantomima representada por La Sorbona y Buffon, y las burlas de este último respecto a la condena de su teoría 
de la Tierra, lo ponen claramente de manifiesto ${ }^{38}$. Sea como fuere, que la Iglesia no negara lo ya evidente para todos, quizás pueda considerarse un mérito, pero que pretendiera permitirlo constituye lo que sin duda no es sino un exceso de celo en el esfuerzo de propiciar ese "diálogo constructivo entre científicos y teólogos", del que habla Juan Pablo II" ${ }^{39}$.

Pero la línea de argumentación básica ya estaba trazada desde un principio y la reencontramos desarrollada hasta un punto extremo en sendos memoriales de un ex-jesuita, el padre Girolamo Tiraboschi, de 1792 y 1793 . Éste afirma que Galileo violó el decreto de 1616 y ridiculizó la teoría geocéntrica, mostrándose imprudente y obstinado, y que fue excesivo prohibir el sistema copernicano. A partir de ahí, tras constatar que, según le resume D'Addio, «la difusión y profundización de la teoría copernicana fueron un mérito de Italia y de la Iglesia" ${ }^{40}$, Tiraboschi desarrolla el argumento de Riccioli:

"señalaré solamente que Galileo no fue condenado por la Iglesia universal, ni por la romana, sino sólo por el tribunal de la Inquisición, al que ningún teólogo, ni siquiera de entre los más celosos, ha atribuido jamás el derecho de la infalibilidad; y que antes bien el ponderar que la Iglesia, incluso en aquellos tiempos, en los que se creía generalmente que la doctrina de Copérnico y de Galileo era contraria a la Sagrada Escritura, no la condenara como herética, nos hace ver con cuanta cautela procede ésta en sus solemnes decisiones" ${ }^{41}$.

No parece que los inquisidores, a pesar de esa "cautela" que tan generosamente se les atribuye, tuvieran en cuenta esa carencia de infalibilidad en sus censuras y condenas de toda clase. Quizás es porque no las considerara decisiones suficientemente "solemnes". En todo caso, me temo que esto no modificaba en absoluto el sufrimiento que infligieron.

Nótese que aquí ya se corta por lo sano: simplemente se niega la existencia de la condena por herejía. Según Tiraboschi, Galileo fue condenado por desobedecer a la admonición de 1616. El Maestro del Sacro Palazzo criticó a Tiraboschi, entre otras cosas, por aceptar que la teoría copernicana había quedado demostrada. Brandmüller, comenta la fina ironía de Tiraboschi en su respuesta, pero después nos sorprende con la siguiente afirmación:

«el sistema copernicano correcto, justificado, elaborado a través de los resultados de casi dos siglos de investigaciones astronómicas, había ido encontrando cada vez más un mayor reconocimiento, o mejor dicho, se había ido haciendo cada vez más obvio, si bien -al menos desde el punto 
de vista actual- sólo los descubrimientos de Friedrich Wilhem Bessel en 1838 aportaron una prueba convincente a favor de aquel sistema” ${ }^{42}$.

Una afirmación de apariencia erudita y escrupulosa que, sin embargo, es simplemente una tontería.

Lo que sería pertinente, si quisiéramos ser realmente escrupulosos y precisos, sería considerar hasta qué punto los descubrimientos de Bessel, o de Bradley, o de Foucault hubieran representado una demostración para aquellos que, como Urbano VIII o Bellarmino, entre 1616 y 1633 , negaban la existencia de una prueba del movimiento terrestre en particular, y de la teoría copernicana en general. Desafortunadamente no podemos extendernos sobre este punto aquí. Pero fue tratado con detalle por Morpurgo-Tagliabue. Valga comc resumen este texto suyo que toca un punto central que me interesa destacar aquí. Tras citar la Carta de Bellarmino a Foscarini en la que, como es bien sabido, el cardenal insistía en que no se había dado una "verdadera demostración" del movimiento terrestre y la centralidad del Sol, y añadía que no creía que se hallara tal prueba, comenta Morpurgo-Tagliabue:

"Verdadera demostración. ¿Qué significa esto? Una demostración katà fusin y no katà symbebekos. Por deducción de definiciones concernientes a la esencia de los cuerpos, y no por suposiciones sacadas de las apariencias accidentales... la prueba de la aberración de las estrellas (1728), la prueba de la paralaje (1837), la del péndulo de Foucault (1851)... Basta observar que incluso cada una de estas pruebas más recientes habría parecido a la Mentalidad de entonces [entiéndase de Bellarmino] un "salvar las apariencias", un argumento katà symbebekos, no una demostración. Para aclararlo con un ejemplo: sólo si Galileo hubiese ofrecido un sistema cosmológico deductivo sacado como un todo de un principio axiomático (que en su caso habría podido ser la ley de la inercia), sólo entonces, quizás, un Bellarmino habría estado dispuesto a pensar en una "verdadera demostración" ... Lo que es seguro es que con "verdadera demostración" no pensaba en una prueba experimental" ${ }^{43}$.

Pero, en sus textos, Brandmüller no analiza nunca mínimamente ni un sólo argumento teórico. Da o quita la razón con rotundidad, pero las razones no parecen importarle mucho ${ }^{44}$.

Así llegamos a 1820, con el caso de Settele, Anfossi y Olivieri que concluiría con uno de esos logros que sólo la Iglesia es capaz de conseguir: la aceptación del copernicanismo sin entrar en contradicción con la condena anterior de éste. Verán. 
A finales de 1819, principios de 1820, el padre Giuseppe Settele solicitó el imprimatur para su obra Elementos de Optica y de Astronomía, en la que se afirmaba abiertamente el movimiento de la Tierra. El Maestro del Sacro Palazzo, Filippo Anfossi dio una respuesta negativa, apoyándose en los decretos de 1616 y 1633. Pero ahora, en 1820, hacía siglos que se publicaban obras copernicanas sin problemas y la teoría copernicano-galileana era universalmente aceptada. Las autoridades eclesiásticas lo sabian muy bien. Hasta ahora, habían fingido que no existía problema. Pero la decisión de Anfossi obligaba a reconocerlo. El Papa no se decidía a obligar a Anfossi a dar el imprimatur, porque temía que éste organizara un escándalo público.

El gran problema que se plantearon explícitamente fue cómo se podía autorizar el heliocentrismo, condenado en 1616 y en 1633 y, a la vez, salvaguardar el crédito de la Santa Sede. Naturalmente encontraron el modo de hacerlo. El héroe de esta historia, el padre Maurizio Benedetto Olivieri, Socio del Comisario del Santo Oficio, y posteriormente Comisario él mismo, concibió inmediatamente las líneas maestras de la táctica a seguir ${ }^{45}$. Sus tesis fueron recogidas por el Procurador General de la Orden de los Barnabitas, el padre Antonio María Grandi, designado por la Comisión creada con el único fin de idear y decidir el modo ad tuendam decentiam $S$. Sedis ("que salve el decoro de la Santa Sede") ${ }^{46}$. Grandi adujo un argumento propio muy agudo: es cierto que, en 1616, la teoría copernicana fue condenada como falsa y contraria a la Sagrada Escritura, pero también lo es que este Decreto se mitigó, a partir de 1620 , al permitir que la teoría fuera tratada como hipótesis. Por tanto, «no se puede presumir que hubiera sido juzgada errónea, y mucho menos herética la afirmación del movimiento de la Tierra». El sólido fundamento de esta extraña argumentación la da Grandi a continuación y radica, en definitiva, en la bondadosa preocupación pastoral de la Iglesia por sus ovejas.

«Pero jamás puede suponerse que, si este sistema hubiese sido juzgado erróneo o herético, la Iglesia hubiera permitido sostenerlo como hipótesis; eso para no poner en peligro, a los que lo estudiasen, de pecar contra la fe, si el sistema les pareciera demostrado nor la evidencia" ${ }^{47}$.

Es cierto que, sólo en la primera página, la propuesta de Grandi consigue aunar la falsedad, la contradicción y la escalada libre. No se trata sólo de que un hombre de sólidos principios no se deja arredrar fácilmente por los hechos. Sino que, para "salvarle la cara" a la Iglesia, Grandi no tiene que hacerle la cirugía estética a la Santa Sede, sino 
«Una reflexión serena y objetiva». Galileo y el...

a los hechos históricos. Sin un falseamiento de la realidad, no se podía salvar el decoro, porque de lo contrario no habría habido decoro que salvar.

Contra lo que podría pensarse, Anfossi no se quedó solo y aislado. Nueve meses después de iniciado el asunto, el papa Pío VII seguía dudando si dar su aprobación al imprimatur del libro de Settele y a la aceptación del copernicanismo. Cuando Anfossi le presentó un opúsculo, al que me referiré a continuación, en el que justificaba su negativa a conceder el imprimatur a una obra que defendía una teoría condenada, el Papa envió a su limosnero, monseñor Bertazzoli, a hablar con Settele, con el recado de que quería "que propusiese la cosa como hipótesis", que era lo que había sugerido Anfossi. Y cuando Settele contesta que la Inquisición ya le había dado indicaciones de publicar, a la espera del imprimatur, Bertazzoli insiste en que el Papa está por encima de la Inquisición. Sólo el hecho de que los periódicos ya han informado en el extranjero de que la Inquisición se ha decidido en favor de la publicación detiene la coacción. Las razones del Papa que expone Bertazzoli no pueden ser más transparentes:

«Dijo también que lo que una vez era contrario a la Sagrada Escritura seguía siendo contrario siempre; que Anfossi no andaba del todo desencaminadon ${ }^{48}$.

Pero en esta historia todo está trastocado, y la Inquisición, la misma institución que condenó la teoría copernicana e incluyó en el Indice de libros prohibidos las obras que la sostenían, ahora quiere obligar a conceder el imprimatur a una obra que defiende el copernicanismo como verdad física. Anfossi que simplemente se remite al Decreto condenatorio de la Inquisición, ahora es considerado un "loco" que dice "tonterías" ${ }^{49}$. Y si un Papa había impulsado aquella condena ahora otro Papa es criticado duramente por sus colaboradores por no decidirse de una vez a retirarla. Settele, en su Diario, empieza hablando de Pío VII como «un gran taimado" y después de un año ya no tiene dudas "el Papa, siendo tan imbécil..." ${ }^{50}$. Uno podría pensar que está excesivamente alterado por un excesivo amor a su obra cuya publicación ve entorpecida. Pero el propio Olivieri habla reiteradamente de la «irresolución" del Papa, de que "no las tiene todas consigo", y le culpa del retraso ${ }^{51}$. Aunque sin duda el colmo de la irreverencia se alcanza cuando en un documento oficial, aunque sea posterior a la muerte de Pío VII, el Secretario de la Congregación del Indice, el padre Bardani culpa del retraso a "la indolencia y estupidez del propio Papa" (ob 
eiusdem Pontificis oscitantiam et obstupescentiam)" ${ }^{52}$. Éste es un terreno muy peligroso para los que pretenden defender la respetabilidad del Papa simplemente por serlo.

Pero lo que resulta más desconcertante en este punto es que no se entiende desde qué firmeza y claridad moral y de ideas habla Olivieri. Se supone que él y la Inquisición, de la que es Comisario, se han visto entorpecidos por la cerrilidad de Anfossi, el Maestro del Sacro Palazzo, y las dudas del Papa. Pero lo cierto es que, cuando finalmente se decide autorizar la publicación, la Inquisición exige que «el libro se publique sin divulgación ninguna, es decir, sin pegar la portada por Roma" ${ }^{53}$. Y además, la Inquisición se niega explícitamente a aparecer en el libro de Settele como responsable del imprimatur, que viene firmado sólo por el Arzobispo Frattini. Olivieri explica que

«la Inquisicion ha querido seguir el mismo método que utilizó inmediatamente después del caso Galileo, es decir dejar circular esta opinión sin oponerse" ${ }^{54}$.

Así pues, el tirar la piedra y esconder la mano no parece que sea un principio demasiado limpio y sólido para permitir el desprecio de las dudas del Papa. El propio Settele lo resume con bastante claridad, cuando enumera las razones que se le ocurren para explicar que la Inquisición no quiera verse públicamente relacionada con el asunto:

"A las precedentes razones se podría añadir una cuarta, esto es que si ahora se publicase el Decreto hecho, se le podría echar en cara -a la Inquisición - el decreto contra Galileo, y decirle en suma que una vez se equivoc6́. Pero no publicando ningún Decreto, no se puede hacer la comparación, como se ve, puesto que lo permite, pero no se sabe cómo, no se tienen documentos que traer a colación y se sigue en la incertidumbre. De hecho, me acuerdo que monseñor Bertazzoli, cuando yo le dije que esta prohibición podría provocar reacciones contra Roma, me dijo que quizás provocaría más aún si ahora el Santo Oficio lo permitiese, que se podría decir que una vez se había equivocado. Ciertamente los curas son taimados, ven que ya no pueden resistirse a la evidencia, tienen ante los ojos el decreto contra Galileo, y toman esta decision, es decir no oponerse a la opinión actual, sin reprobar la conducta de entonces ${ }^{55}$.

Con esos renglones torcidos se concedió por fin el imprimatur y el Poterit imprimi el 26 de diciembre de 1820. Todo parecía resuelto por fin. Pero no lo estaba. En 1822, un médico llamado De Crollis 
«Una reflexión serena y objetiva». Galileo y el...

quiso publicar en el Giornale Arcadico un Estratto del libro de Settele. Pues bien, Anfossi se negó de nuevo a conceder el imprimatur. Fue entonces cuando Olivieri, el héroe de Brandmüller, decidió «pasar a la ofensiva». La Secretaria de Estado desautorizó a Anfossi y la Congregación del Indice decidió en su reunión del 2 de septiembre de 1822 recomendar la retirada del Indice de los nombres de Copérnico, Zúñiga y Foscarini. Los consultores del Santo Oficio empezaron a pensar en el asunto. Lo pensaron mucho. En diciembre de 1823 todavía decidieron seguir madurando la decisión, incluyendo en su reflexión los casos de Kepler y Galileo. Las fuentes documentales disponibles ya no informan sobre la sesuda reflexion de los doce años siguientes. Simplemente sabemos que en la edición del Indice de 1835 la obras de estos autores ya no figuraban. En 1616, cuando todo era más discutible, la Inquisición apenas necesitó quince días para examinar la teoría copernicana y publicar el decreto de condena. Ahora, cuando todo estaba claro, la Inquisición necesitó quince años para retirar del Indice a Copérnico y Galileo. Pero veamos brevemente los argumentos centrales de una y otra parte, es decir de Anfossi y de Olivieri, desde que empieza el problema con la solicitud del imprimatur para el libro de Settele.

Resulta muy revelador lo diáfano de los argumentos de Anfossi ${ }^{56}$. Está claro que defendía las tesis y decisiones que la propia Iglesia había utilizado en su condena en 1616 y 1633, tesis y decisiones que, como sabemos, no habían sido revocados. En eso consistía la fortaleza de su posición: aún era la posición de la Iglesia. Lo cual podía convertir las sonrisas de suficiencia de Olivieri en rictus de crispación. Los puntos básicos de la posición de Anfossi pueden resumirse como sigue:

El Maestro del Sacro Palazzo, en su tarea de censor, regulada por la constitución del quinto concilio lateranense,

«no regula su juicio por las teorías de los filósofos y de los astrónomos, sujetas a mil excepciones y errores, sino por la doctrina de la Iglesia fundada en las Escrituras, en la Tradición, en los Padres y en las definiciones de la Santa Sede Apostólica" ${ }^{57}$.

De ahí la condena del libro de Settele, que defendía una teoría inequívocamente condenada como herética.

Además, los argumentos esgrimidos para atenuar la condena de 1616, no tenían ningún valor. No sólo había sido formulada por los once calificadores, todos ellos excelsos teólogos, sino que fue ordenada por el Papa y la Congregación del Santo oficio. Y el Papa ordenó a 
Bellarmino amonestar a Galileo, e intervino el Comisario del Santo Oficio, etc.

«Así pues, -concluye Anfossi- la censura y la condena de la doctrina contraria no podía ser ni más auténtica ni más solemne” ${ }^{58}$.

Settele había hecho, como todo el clero, la Profesión de Fe Tridentina, por la que se comprometía a interpretar la Escritura como la Iglesia y no como los astrónomos. Y la interpretación de la Iglesia «ha sido siempre y es contraria a la inmovilidad del Sol y la movilidad de la Tierra". La tesis copernicana "sólo puede defenderse como hipótesis" ${ }^{59}$.

El argumento de que en la edición del Indice de 1758 se eliminó la prohibición genérica de los libros que enseñaban el heliocentrismo no tiene ningún valor. Eso no equivale en absoluto a aprobar que se enseñe la teoría copernicana. Las medidas disciplinarias pueden cambiarse, pero la doctrina es irrevocable: «ha sido y será siempre la misma" ${ }^{60}$. Anfossi replicaba también a un argumento de un texto posterior de Settele. Éste afirmaba que, en 1616, la teoría copernicana había sido condenada por absurdos filosóficos que ya habían sido desechados. Ahora las pruebas, como el peso del aire descubierto por Torricelli, la aberración estelar, etc. la hacían aceptable. Anfossi es tajante: la Iglesia funda sus juicios doctrinales en la Escritura y los Santos Padres y, por tanto, los descubrimientos que pudieran fortalecer la teoría copernicana, como por ejemplo el del peso del aire de Torricelli, "nunca hará que sea de otra manera" ${ }^{61}$. Anfossi insiste en que Settele

«no comprende el absurdo perniciosísimo al que lleva el hacer depender la verdadera comprensión de las Escrituras, no de la asistencia del Espíritu Santo, sino de los descubrimientos posteriores en 17 siglos a la fundación de la Iglesia” 62 .

Pues bien, a pesar de esa fidelidad a la letra y sobre todo al espíritu de 1616 y 1633 , o precisamente por ella, resulta que Anfossi es un pobre ignorante que muestra una obstinación irracional. Un hombre que, según dice reiteradamente Olivieri, hay que compadecer, pero también refutar. Ahora el Comisario de la Inquisición, quién iba a decirlo, se constituye en el gran defensor de la teoría copernicana, frente al Maestro del Sacro Palazzo.

Las respuestas de Olivieri ${ }^{63}$ son, comprensiblemente, algo más enrevesadas. En especial, enreda el argumento de Settele mencionado 
«Una reflexión serena y objetiva». Galileo y el...

más arriba. Según Olivieri pueden distinguirse dos tipos de «movilidad de la Tierra", una física, absurda y desastrosa, y otra astronómica, pacífica y justificada. La que condenaron los téblogos de 1616 era la primera:

«era aquella con la que se quitaba el centro a los graves.. la que se apartaba la Tierra de su aire que la circunda. De lo cual debían nacer extremos desbarajustes" ${ }^{64}$.

Copérnico y Galileo no había sabido evitar estas consecuencias catastróficas y por eso esa movilidad terrestre fue prohibida. Pero se permitía como hipótesis astronómica porque, aunque fuera falsa, concordaba con los fenómenos celestes.

Ya hemos visto cuál es la réplica de Anfossi, que parece relevante. Pero, en la medida en que el argumento de Olivieri no es puramente retórico, se basa en una falsedad y en un punto por lo menos muy discutible. En primer lugar, no es cierto que, en 1616 y 1633, la tesis del movimiento terrestre hubiera sido condenada por razones filosoficas que la hacían absurda ${ }^{65}$. Fue condenada por ser contraria a las Escrituras. Eso de por sí podría zanjar la cuestión, puesto que es el punto crucial de toda la argumentación de Olivieri. Este afirma que la condena se debió a problemas teóricos insuperables en aquellos momentos. Una vez superados, por tanto, la teoría puede ser considerada diferente y afirmarse. Pero el hecho es que la teoría no fue condenada por estar insuficientemente justificada teóricamente ${ }^{66}$.

Por otra parte, ¿por qué debemos dar por sentado, como hace Olivieri, el carácter catastrófico de la movilidad de la Tierra en 1633? Aunque aceptáramos la afirmación de que Galileo no pudo dar argumentos satisfactorios para justificar adecuadamente su posición, algo por lo menos discutible, eso no permite deducir, como acabo de señalar, que sus jueces tuvieran razones satisfactorias para defender la posición tradicional, es decir para negar los argumentos galileanos o justificar los propios. De hecho, Galileo escribí la primera jornada del Diálogo para poner de manifiesto esta petición de principio y los sofismas derivados. Dicho brevemente, lo que resulta indudable es que Galileo había mostrado las carencias argumentales de sus adversarios, mucho más claramente de lo que éstos habian sido capaces de rechazar sus tesis. Los argumentos de Galileo aún no eran los de Newton. Pero lo que ya estaba totalmente claro es que los argumentos aristotélicoptolemaicos ya no tenía ninguna opción. 
La condena del copernicanismo nos sitúa ante el ejercicio del poder absoluto por parte de la Iglesia y sus inquisidores, no ante la contundencia de sus argumentos, en la medida en que los tuvieran.

La típica retórica del poder de otros argumentos de Olivieri no acepta disimulo. Afirma, por ejemplo, que no hay un sólo texto bíblico que vaya contra los movimientos de rotación y de traslación de la Tierra ${ }^{67}$. Naturalmente, acoge con entusiasmo la tesis de que las condenas de los decretos de 1616 y 1633 no constituían materias de fe ni eran irrevocables ${ }^{68}$.

Pero la parte más burda y sangrante es, sin duda, la consideración que hace Olivieri de la abjuración de Galileo:

"ponderando esta abjuración de Galileo, se pone de manifiesto que se tuvo con él tanta condescendencia que pudo pronunciar esta fórmula con un significado obvio, sin escamotear su íntima convicción, y que un astrónomo moderno, por lo que toca a la parte doctrinal, podría pronunciarla ahora sin dificultad" ${ }^{69}$.

El argumento de Olivieri reza como sigue. Galileo abjuró de dos proposiciones: 1. «El Sol está inmóvil en el centro del mundo»; 2. "La Tierra no es el centro y se mueve». Veamos ahora, dice, si Galileo podía creer "sin fingimiento alguno" las proposiciones contrarias. Según Olivieri, Galileo sabía que

"nuestros graves caen hacia el centro de la Tierra, y no hacia el Sol. Por lo cual con absoluta veracidad afirmaba "Solem non esse in centro mundi». (Idem)

Ya que la abjuración al referirse al movimiento del Sol no incluía las expresiones "con movimiento local" o "de Oriente a Occidente" de la condena, y dado que el propio Galileo había descubierto el movimiento de rotación del Sol sobre su eje, podía afirmar con total honestidad «el Sol no es inmóvil».

En cuanto a la abjuración de la no centralidad de la Tierra y de su movimiento, Olivieri pregunta:

"Ahora bien, ¿Quién no se da cuenta de que la Tierra es el centro de los graves de alrededor que caen hacia ella; centro del agua... -Y más adelante- ¿Acaso no es inmóvil respecto a todo lo que se genera y se corrompe y a cualquier cosa que acaezca sobre ella, que sigue siendo siempre el firme suelo inmóvil? ¿No lo es respecto a todos los graves, cuya dirección hacia su centro permanece inmóvil?... ¿...respecto a todos los movimiento propios que se dan sobre ella?" ${ }^{70}$. 
«Una reflexión serena y objetiva». Galileo y el...

Por tanto Galileo pudo creer que la Tierra es el centro y que está inmóvil, y abjurar de lo contrario sin fingimiento ninguno. El argumento es tan pedestre desde un punto de vista histórico y teórico que no merece análisis ninguno. Pero no sé si llevar el intento de salvar el decoro de la Iglesia hasta el sadismo es una buen sistema de conseguir el objetivo.

Porque, recuérdese que la cuestión que se estaba afrontando era cómo la Santa Sede podía tener una buena imagen si revocaba la prohibición de libros que antes había condenado. Pues bien, «La respuesta es inmediata -escribe Olivieri- La tendrá incluso bonísima" ${ }^{71}$, porque las circunstancias y la teoría prohibida han cambiado. ¿Y no se ofendía a la Congregación que en $\mathbf{1 7 5 8}$ dejó en el Indice estos libros copernicanos? En absoluto, contesta Olivieri. Aquellos doctísimos censores eran pocos para miles de libros. Nosotros somos más y llevamos años ocupándonos sólo de cinco libros. Si ellos hubieran tenido la posibilidad de examinar uno a uno, con la misma atención que ahora, todos los libros, ya los hubieran eliminado del Indice ${ }^{72}$.

Lo más fascinante es que, para salvar la cara de la Santa Sede y de los censores eclesiásticos anteriores, se aduzca que iprohibían los libros no porque los revisaran escrupulosísimamente, sino porque no tenían tiempo de revisarlos adecuadamente!

Pero no se trata sólo de que lo creyeran efectivo hace más de un siglo y medio. En 1992, Brandmüller está deslumbrado por la altura intelectual y sutileza de Olivieri. Y afirma asombrado que Olivieri

«demostró una gran erudición y sagacidad. Consiguio demostrar de modo convincente que la Santa Sede censuró el heliocentrismo en 1616 por motivos tan válidos como los usados para aceptarlo en 1820, sin ganarse la acusación de haber cambiado de opinión. Con esta prueba, y sobre todo con el modo en el que la presentó, Olivieri honró grandemente al Santo Oficio" ${ }^{73}$.

Más aún, Brandmüller observa que el examen de la actitud de la Iglesia ante Copérnico y Galileo nos ofrece sorprendentes conclusiones:

"La primera consiste en que, en la época de Galileo, la exigencia del Santo Oficio, o mejor de la Congregación del Indice, de sostener el heliocentrismo sólo como hipótesis aparece plenamente justificada desde el punto de vista de la actual teoría crítica de la ciencia. Sto. Tomás de Aquino era quien había formulado el principio seguido por los té́logos romanos, que así evitaron caer en un optimismo hacia las ciencias... 


\section{Antonio Beltrán}

Olivieri nunca afirmó que el movimiento de la Tierra y el heliocentrismo fueran verdades incontrovertibles... La argumentación de Olivieri mostraba simplemente que se puede enseñar esta concepción astronómica sin contradecir la fe católica. Esta reserva posteriormente se ha mostrado justificada, visto que el sistema de Copérnico, de Galileo y de Newton ya ha sido superado desde hace tiempo por la investigación. Y precisamente este desarrollo confirma nuevamente el escepticismo metodológico de los té́logos romanos de 1616 basado en Santo Tomás de Aquino. Con esta constatación, por tanto, el Santo Oficio había respetado estrictamente los limites de sus competencias tanto teológico-científicas como eclesiástico-magistrales».

Quedaba creada así, por parte de la Iglesia una premisa importante para un diálogo fructífero entre ciencia e Iglesia» ${ }^{74}$. En otras palabras, que lo que parecía ser una rehabilitación de Galileo, ha resultado sobre todo una rehabilitación de la Santa Inquisición. No es extraño que el Papa quedara contento con esta "reflexión serena y objetiva del caso Galileo" de esta "cualificada personalidad" que es el ínclito Brandmüller.

A estas alturas, la manipulación ha alcanzado tal nivel que los decretos inquisitoriales de 1616 y 1633 , condenando el copernicanismo y a Galileo, han adquirido el mismo status polisémico y político que los textos de las Sagradas Escrituras. Es decir, dicen simple y llanamente lo que la Iglesia católica quiere que digan; independientemente de lo que digan, naturalmente. Y lo que es más envidiable aún, la Iglesia católica puede decidir en un momento determinado que un texto dice clara e inequivocamente $A$, y algún tiempo después decidir que ese mismo texto dice no- $A$, sin caer en contradicción. En el caso de la Iglesia católica no se trata de contradicción, se trata de progreso.

Juan Pablo II, lo expresó de un modo muy gracioso, en noviembre de 1980 , cuando aludiendo a los "famosos conflictos" de antaño entre la Iglesia y la ciencia decía que hoy estaban superados ${ }^{75}$.

"gracias sobre todo al trabajo de una teología científica, que profundizando la comprensión de la fe la ha librado de los condicionamientos del tiempon ${ }^{76}$.

Se lo resumo. Principio básico agustiniano que facilita mucho las cosas: lo que se opone a la verdad no es el sentido genuino de la Escritura. Antes la Iglesia se atrevía a aceptar el sentido obvio de algunas afirmaciones del Texto Sagrado. Dado que así se equivocó entrando en conflicto con "verdades" de la ciencia, ahora ya no nos 
«Una reflexión serena y objetiva». Galileo y el...

comprometemos con ningún sentido concreto. Invertiremos el proceso. Los teólogos se informarán de las adquisiciones científicas y, cuando parezcan firmes y "si es oportuno", las tomarán en cuenta para determinar lo que, sin duda, es y siempre ha sido el sentido de los textos bíblicos afectados. Y, como determina el Papa Juan Pablo II, la Academia Pontificia de Ciencias tiene la delicada misión de

«discernir y dar a conocer... lo que se puede considerar como verdad adquirida o se halla al menos dotado de tal probabilidad que resultaría imprudente e irrazonable rechazarlo" ${ }^{77}$.

Naturalmente, esto se complementa con otra noble tarea de la Academia Pontificia: "promover el desarrollo de los conocimientos, según la legítima autonomía de la ciencia» y defendiendo la «libertad de investigación», como ya proclamara el Vaticano II, el gozoso parágrafo 36 de la Gaudium et Spes, que comentaré a continuación ${ }^{78}$.

La historia con la que quiero terminar ilustrará diáfanamente, si lo dicho hasta aquí no hubiera bastado, cómo la Iglesia entiende esa "autonomía de la ciencia" y cómo favorece la "libertad de investigación".

Empieza de nuevo en la Academia Pontificia de Ciencias y también tiene que ver con el "caso Galileo". En diciembre de 1941, el Santo Padre Pío XII, inauguraba el curso académico en la Academia. Agostino Gemelli, presidente de la misma, en un texto que reproduciría L'Osservatore Romano del 1 de diciembre de 1941, anunciaba que, dado el inminente centenario de la muerte de Galileo, en 1942, una comisión de la Pontificia había elegido a Pío Paschini, Rector Magnifico del Pontificio Ateneo Lateranense, para que escribiera una obra sobre Galileo. Una obra que, contextualizándolo debidamente, "reubicaría la figura del gran astrónomo en su verdadera luz". Gemelli comentaba:

"Así pues, el proyectado volumen será una eficaz demostración de que la Iglesia no persiguió a Galileo, sino que lo ayudó generosamente en sus estudios. Sin embargo, no será una obra apologética, porque éste no es el propósito de los científicos, sino de documentación científica e histórica" ${ }^{79}$.

Pío Paschini tenía fama de historiador serio y honesto, ajeno al partidismo apologético y por eso, se le dijo, se había pensado en él. Aceptó a regañadientes, porque nunca había abordado el campo de la historia de la ciencia, ni la obra de Galileo. Pero trabajó intensamente durante cuatro años en la preparación de su Vita di Galileo, leyendo los volúmenes de la edición de Favaro de Le Opere de Galileo, así 
como una amplia bibliografia adicional. A lo largo de los cuatro años que dura la investigación, el Papa se interesa reiteradamente por su Galileo y le anima a continuar.

Finalmente, en la primavera de 1944 el libro está terminado y el Pontífice muestra su alegria. Pero el científico de la Academia que tenía que revisar la parte científica cree que en el libro hay "un exceso de acritud contra los jesuitas". El libro pasa a manos del Santo Oficio, con el beneplácito de Gemelli y del Papa, porque la obra se considera "no oportuna». Tras larga espera, ante la insistencia de Paschini, Gemelli le escribe una nota escueta y glacial

«de forma absolutamente reservada, para aconsejarle que no publique bajo ningún concepto la conocida obra. La Academia no le preguntará nada. No hable de esto con nadie. Cuando vuelva a Roma me alegrará verle e informarle de cuanto le escribon ${ }^{80}$.

A partir de ahí empieza un largo silencio. Gemelli da la callada por respuesta a las cartas de Paschini. Éste exige la devolución del manuscrito. En mayo de 1946 Giovanni Battista Montini, sustituto en la Secretaría de Estado, que no es otro que el futuro Papa Pablo VI, le deja ver «una especie de deliberación del Santo Oficio" contra su Galileo ${ }^{81}$.

«en el que se decía que mi trabajo era una apología de Galileo... -cuenta Paschini- y se me objetaba que Galileo no aportaba pruebas de sus sistemas (¡de nuevo el acostumbrado sofisma!) y se concluía que no se creía oportuna la publicación y se me devolvía el manuscrito" ${ }^{82}$.

Pero la continuación de Paschini merece ser citada in extenso:

"he quedado firmemente convencido de que, en el Santo Oficio, no se deseaba una publicación de esta clase desde un principio. La quería la Academia Pontificia de Ciencias, el Papa la aprobaba, pero no el Santo Oficio. Me duele no obstante la poca claridad y la poca, incluso ninguna, hombría del padre Gemelli. Figúrate si yo, que no he sido nunca apologista de nadie, lo seré de Galileo... ¡ $\mathrm{Si}$ ellos han cometido un gran despropósito hace siglos (y no es el único), nosotros hoy deberemos cometer una deshonestidad! Y pensar que se me había recomendado ser objetivo, imparcial etc., etc. Que los jesuitas y los dominicos no hacen un buen papel es claro como la luz del Sol, y no les gusta que se lo digan. Sin embargo, puede ser que no hayan intervenido directamente (de hecho no sé si han leído mi manuscrito) y que esté de por medio el prejuicio de que los superiores siempre tienen razón, especialmente cuando están equivocados, como decía aquel" ${ }^{83}$. 
En todo caso, no hay condena ni respuesta oficial ninguna y Paschini sigue esperando un desenlace. En junio de 1946, habla con los inquisidores, y empiezan las humillaciones. Le proponen comprarle el manuscrito en compensación por el perjuicio de no publicarlo. Según el propio Paschini, «quieren acallarlo todo con unos miles de liras" ${ }^{84}$.

Paschini murió a finales de 1962, tras veinte años de silencio impuesto sobre su obrạ prohibida sólo oficiosamente. Su manuscrito acabaría en la Biblioteca Pública del Seminario de Udine.

Poco después, se estaba celebrando el Concilio Vaticano II. Parecía a muchos el comienzo de una nueva etapa. Maccarrone, tendencioso biografo de Paschini, gestiona la posibilidad de publicar su Vita de Galileo. El Papa Pablo VI lo ve con buenos ojos. Es un gesto que hace juego con las nuevas relaciones que él quiere instaurar entre la Iglesia y el mundo. Y la Inquisición deja el asunto en manos de la Academia Pontificia. El presidente de ésta, el Padre Lemaltre, que no quería publicar la obra de Paschini, "porque no le parecía que estuviera al corriente de los más recientes progresos en las ciencias", acepta finalmente que se publique bajo los auspicios de la Academia,

«a condición de que fuera precedida de una Nota Introductoria del Padre Lamalle y de una revisión del texto por parte de ésten ${ }^{85}$.

Así pues, en 1964 la Academia Pontificia de Ciencias publicaba la "edición oficial» de la Vita e opere di Galileo Galilei de Paschini. En su Nota introductoria el jesuita Edmond Lamalle comenta:

"Así mismo, nuestras intervenciones ya sea en el texto, ya sea en las notas, han sido voluntariamente muy discretas, limitándose a algunas rectificaciones que nos han parecido indispensables y a un mínimo de rejuvenecimiento bibliográfico» ${ }^{86}$.

Pues bien, en 1979, Pietro Bertolla, tras un minucioso cotejo del manuscrito y la edición publicada por la Academia Pontificia, detectó más de cien modificaciones de Lamalle, muchas de las cuales traicionan drástica y totalmente las tesis principales de Paschini. Especialmente las que afectan al tema de las pruebas de Galileo, a la condena de 1616, al juicio de Galileo en 1633 y a la responsabilidad de los jesuitas en la condena de Galileo. 
He aquí una mínima muestra de esas "muy discretas intervenciones".

\section{MANUSCRITO}

p. 33

El, de hecho, añade Clavio, "asume hipótesis del todo extravagantes...

\section{p. 270}

Pero a Mayr no le bastó el haber ayudado a Capra en su indigna acción porque trató de reivindicar para sí el hallazgo y el estudio...

\section{p. 314}

... de su prioridad es importante esta afirmación de Welser; en todo caso...

\section{p. 370}

Finalmente expone una visión soberbia sobre la composición del universo: «Diría...

\section{p. 408}

No se habría podido decir mejor, y Galileo pensaba que era capaz de hacerlo; lo más difícil era conseguir convencer a los adversarios iy qué adversarios Teniendo además...

\section{EDICIÓN OFICIAL. LAMALLE \\ p. 34}

Pero Clavio había visto que Copérnico no aportaba pruebas de su posición y que tenía que introducir de nuevo en los cálculos la complicación de los epiciclos. Así pues, adopta sus cálculos, pero no la teoría. Copérnico, concluye Clavio, "asume hipótesis del todo extravagantes...

p. 215

Pero si Mayr sigue siendo sospechoso de haber ayudado a Capra en su indigna acción, mucho más ofensivo fue Galileo cuando trató de reivindicar para sí el hallazgo y el estudio...

p. 253

... de su prioridad es importante esta afirmación de Welser, en tanto avala la buena fe de Scheiner al afirmar la independencia de sus observaciones; en todo caso...

p. 303

Finalmente expone una visión personal más bien abstracta y confusa, sobre la composición del universo. Se trata de expresiones que sorprenden sobre todo escritas por Galileo..

«Diria...

p. 335

No se habría podido decir mejor, y Galileo pensaba que era capaz de hacerlo; sabemos ahora cuanto se engañaba, no tanto respecto a la resistencia que habrían opuesto sus adversarios cuanto sobre el propio valor probatorio de 


\section{p. 413}

Así terminaba lo que impropiamente se llama el primer proceso de Galileo. Digo impropiamente, porque el procedimiento iniciado con una denuncia contra él y sus escritos, dejó al margen a su persona y a sus escritos para dirigirse contra la doctrina copernicana y llegar a la condena con una sentencia pronunciada con una ligereza del todo insólita por parte del austero Tribunal.

Lo peor es que no se volvió a dicha sentencia con un examen más ponderado. Los peripatéticos habian vencido y no quisieron dejar escapar la victoria tan pronto. En cuanto a Galileo se le hizo callar con un precepto, como se dice con término canónico.

Como si hubiese...

\section{p. 665}

Sigue en las actas del proceso el resto de la abjuración leída por Galileo

\section{p. 666}

Así concluye lo que fue el verdadero proceso de Galileo. En cuanto a las responsabilidades se puede decir francamente "los grandes culpables (de la condena) a los ojos de la historia son los defensores de una escuela anticuada que, viendo caer de su mano el cetro de la ciencia y no pudiendo so- sus demostraciones. De las pruebas que tenía in mente, algunas fundadamente correctas, sin embargo eran incontrolables con los medios de entonces, mientras que las otras, más obvias, eran del todo erróneas, como la deducida de las mareas, que él estimaba la mas convincente.

Teniendo además...

\section{p. 341}

Así terminaba lo que impropiamente se llama el primer proceso de Galileo. Digo impropiamente, porque el procedimiento iniciado con una denuncia contra él y sus escritos, dejó al margen a su persona y a sus escritos para dirigirse contra la doctrina copernicana y llegar a la condena con una desafortunada sentencia, que hoy sorprende en un Tribunal tan ponderado y austero, pero que no causa extrañeza considerándola en el marco de la doctrina y del conocimiento científico del momento. Los peripatéticos habían vencido y no quisieron dejar escapar la victoria tan pronto. En cuanto a Galileo se le hizo callar con un precepto, como se dice con término canónigo.

Como si hubiese...

p. 548

Así concluye el que fue verdadero proceso de Galileo. Para no hacerse una idea completamente inexacta, se debe tener cuidado de no incluir certidumbres o puntos de vista que sólo se han impuesto en los siglos siguientes. Por haber perdido de vista esta cautela, se creyó fácilmente, en el siglo XVIII 
portar que ya no fuese escuchado religiosamente el oráculo que salía de sus labios, se sirvieron de todos los medios, de todas las intrigas, para restituir a su enseñanza el crédito que perdía. Las Congregaciones y su autoridad fueron uno de los grandes medios usados, y su culpa fue haberse prestado al juegon*.

* Rev. d'Historie ecclésiast. VII (1906) p. 358.

Este texto pertenece a una recension hecha por P. Delannoy, en la revista citada, a la obra de E. Vacandard, E'tudes de critique et d'histoire religieuse... La condamnation de Galilée, Paris, Le Coffre, 1905. y XIX, que Galileo aportase pruebas evidentes de sus teorías y que sus jueces habían cerrado los ojos para no verlas. Así pues, todo se reducía a una lucha entre el genio y la ignorancia o el fanatismo. "Se trata efectivamente de una gran causa, porque implicaba un drama del espíritu. La razón científica dio un paso osado, por más que sin aportar aún pruebas decisivas, y este gran paso hace necesaria una refundición de las imágenes familiares ligadas, en la mente del científico y en la del hombre de la calle, a la representación del universo.

$\mathrm{Si}$ admiramos la grandeza del docto que arriesga todo el éxito de sus intuiciones, hay que entender también que hombres de una gran formación y con pesadas responsabilidades, no hayan podido lanzarse a la aventura" *.

Sin embargo, el error consistió en obstinarse después en la posición equivocada.

Como había decidido desde el 16 de Julio...

${ }^{*} \mathrm{R}$. Lenoble en histoire de la science (dir. por M. Daumas en «Encyclopédie de la Pleiade», 1957), pp. 475-476. Los viejos esquemas romanticos se han arrastrado hasta nuestro siglo: "los grandes culpables (de la condena) a los ojos de la historia son los defensores de una escuela anticuada que, viendo caer de su mano el cetro de la ciencia y no pudiendo soportar que ya no fuese escuchado religiosamente el oráculo que salía de sus labios, se sirvieron de todos los medios, de todas las intrigas, para restituir a su enseñanza el crédito que perdía. Las Congregaciones y su autoridad fueron uno de los grandes medios usados, y su culpa fue haberse prestado al juego" *.

* Rev. d'Historie ecclésiast. VII (1906) p. 338. 
«Una reflexión serena y objetiva». Galileo y el...

Ningún historiador serio podría suscribir aún simplificaciones de esta clase.

Pues bien, la «edición oficial» de la obra de Paschini salió a tiempo, según el deseo del propio Papa Pablo VI, para poder ser usado en las discusiones conciliares del Vaticano II. Naturalmente los pr ximos al asunto conocían perfectamente la total falsificación que se había hecho. Pero eso no había sido nunca un obstáculo, ipor qué iba a serlo ahora? Más aún, tras aludir al artículo de Bertolla, Maccarrone comenta

«La documentación así aportada no constituye de hecho una acusación contra el revisor, al contrario, da la prueba de su vasto conocimiento del tema y de la historia de la ciencia en tiempos de Galileo. Se han corregido errores (juna estrella no es un cometa!), introducido añadidos explicativos, atenuado y también cambiado juicios demasiado simplistas y sumarios (no sólo contra los jesuitas). Una discusión sobre tales actualizaciones será útil y positiva si se hace con la cientificidad apropiada" ${ }^{87}$.

Maccarrone no fue el único que mostró esa insobornable e impertérrita deshonestidad. Hubo otros. Pero, ya en 1992, cuando el artículo de Bertolla es bien conocido desde hace 13 años, el conspicuo Brandmüller lo cita sin ningún empacho y dice:

"el editor de la obra había introducido modificaciones en, aproximadamente, cien lugares del texto. Se había hecho necesario acomodar el relato al estado de la cuestión en 1964, con lo que sin duda la obra ganó en rigor. El editor, además, no pudo resistir la tentación de suavizar algunos juicios, poco favorables, vertidos por Paschini sobre los jesuitas y la curia.

También es preciso señalar que ni el propio Paschini se atrevió a abstraer, aplicándolos al siglo XX, sus juicios -por otra parte escasos- acerca de la ciencia y el mundon 88 .

Pero hay más. En las discusiones preparatorias de la comisión plenaria del Concilio Vaticano II, de lo que sería la Gaudium et Spes, hubo numerosas intervenciones que plantearon la conveniencia de mencionar explícitamente la condena de Galileo en relación a la libertad de la ciencia. Finalmente, se impuso la propuesta del Co-Presidente, Monseñor Pietro Parente. 
«Es inoportuno hablar de Galileo en este documento. No pidamos de la Iglesia que diga: yo erré. Hay que juzgar en razón del tiempo. En la obra de Paschini todo se expone todo en su verdadera luz" ${ }^{89}$.

En la comisión plenaria del 7 de abril de 1965 el obispo Mamour André Charue y monseñor Ermenegildo Florit propusieron:

«Es suficiente citar la obra de Paschini. La obra es una manifestación de sinceridad (ostendit sinceritatem) ${ }^{90}$.

La propuesta se aceptó y, finalmente, se silenció cualquier referencia explícita a la condena de Galileo, incluyendo la referencia a Paschini en una nota a pie de página de un texto que no tiene desperdicio. Afirma que la investigación científica

"si está realizada de una forma auténticamente científica y conforme a las leyes morales, nunca será en realidad contraria a la fe... Más aún, quien con perseverancia y humildad se esfuerza por penetrar en los secretos de la realidad, está llevado, aún sin saberlo, como por la mano de Dios... Son, a este respecto, de deplorar ciertas actitudes que, por no comprender bien el sentido de la legítima autonomía de la ciencia, se han dado algunas veces entre los propios cristianos actitudes que, seguidas de agrias polémicas, indujeron a muchos a establecer una oposición entre la ciencia y la fe* (cursiva mía)

* [a pie de página:] Cf. Mons. Pío Paschini, Vita e opere di Galilei. 1.2 , ed. Vatic.(1964)" ${ }^{91}$.

Es tan bonito. Pero, desgraciadamente, no hay duda ninguna de que en el "caso Paschini" no se actuó "de forma auténticamente científica" y menos aún "conforme a las leyes morales". Que se censure, en este contexto, el "no comprender bien la legítima autonomía de la ciencia", resulta tan sarcástico que el insulto a la inteligencia y sentido moral de los lectores parece difícil de superar, y no hay sentido del humor que lo resista.

Sin embargo, Juan Pablo II intentó "ir más allá», creo que con éxito, cuando al iniciar la "auténtica" rehabilitación de Galileo, en 1979 , —l mismo año en que se publicó el artículo aludido de Bertolla-, ante la Academia Pontificia de las Ciencias, citó precisamente este pasaje de reivindicación de la autonomía de la ciencia del Vaticano II, y añadió 
«Una reflexión serena y objetiva». Galileo y el...

«Para ir más allá de esta toma de posición del Concilio, yo deseo que teólogos, científicos e historiadores, animados por un espíritu de sincera colaboración, profundicen el examen del caso Galileo y, en un reconocimiento leal de los errores, vengan del lado que vengan, hagan desaparecer la desconfianza que este caso opone aún, en muchos espíritus, a una concordia fructuosa entre ciencia y fe» ${ }^{92}$.

Ya hemos visto un buen ejemplo de cómo se desarrolló esta "profundizacion". Creo que los sentimientos de desconfianza respecto a la actitud de la Iglesia en relación al "caso Galileo" ya habrán desaparecido. Ahora, tras lo visto, y más que hay, serán sin duda de una seguridad absoluta. Desafortunadamente, la investigación nunca puede alcanzar el mismo eco y difusión que la propaganda sin escrúpulos.

\section{Notas}

1 GaRgantini, 1985, p. 130. Cito las obras con el nombre del autor, seguido del año de publicación y del número de página. Las referencias completas se hallarán en la bibliografia al final del artículo.

2 Idem.

3 Idem.

4 Ibid., p. 131.

5 REDONDI 1990, p. 313.

6 De hecho, Juan Pablo II iniciaba su discurso aludiendo y citando el motu propio de Pío XI: «Me siento plenamente solidario con mi predecesor Pío XI... al invitar a los miembros de la Academia Pontificia de Ciencias, "a hacer progresar cada vez más noblemente y más intensamente las ciencias, sin pedirle nada..." "POUPARD Ed. 1983 , p. 271.

7 Poupard Ed. 1983, p. 5. Expresiones como esta de Monseñor Paul Poupard, así como reivindicaciones de cientificidad, seriedad histórica, y otras virtudes científicas son constantes y características de la mayoría de las publicaciones de la Academia Pontificia de Ciencias y otras instituciones del Vaticano sobre Galileo. Son un indicio casi inequívoco de que nos encontramos ante un apologista. Los científicos o historiadores de la ciencia no parecen sentir la necesidad de llenar sus prólogos o anteceder sus tesis con este tipo de declaraciones.

8 La seccion exegética, dirigida por el cardenal Carlo Martini; la sección cultural, a cargo de monseñor Paul Poupard; la sección científica y epistemológica, encabezada por el padre Georges Coyne S.J.; y la sección histórica cuya dirección cra compartida por Monseñor Michele Garrone y el profesor Mario D'Addio.

9 Cit. en Brandmuller 1992, p. 195-196.

10 A. Beltrán, 1994, pp. LXX-LXXIV. Aludo alli al libro editado por Monseñor Paul Poupard (Poupard, 1983). En corroboración de lo que escribí allí sobre el carácter descaradamente apologético del libro, puede verse el juicio poco sospechoso de Annibale Fantoli, 1997, pp. 474, 478-479, 481-482 y 493-494, donde Fantoli señala la falta de 
rigor de algunas de las afirmaciones vertidas en el libro, siempre favorables a la Iglesia, naturalmente.

11 Walter Brandmuller y Egon J. Greipl (Eds.) 1992.

12 Gallleo, Opere XIX, pp. 320-321; Pagano, 1984, pp. 99-100.

13 Galileo, Opere XIX, p. 322-323 Pagano 1984, p. 103. Finocchiaro 1989, p. 149.

14 Al hablar de la teoría copernicana como de una hipótesis, para Urbano VIII Bellarmino y la Congregación del Indice se trata simplemente de una de las muchás posibilidades lógicas de manejar los datos astronómicos, sin ninguna pretensión de tocar la realidad; un mero "salvar los fenómenos", acaso probable pero nunca falso o falsable. Para Galileo, se trata de una hipótesis en el sentido de una teoría tentativa que la realidad podía corroborar o falsar. Véase MORPURGO-TAGLIABUE, 1963, pp. 52-54; D'ADDIO 1993, pp. 87-89.

15 Nicolas de OREsme, Le livre $d u$ ciel et $d u$ monde, A.D. Menus y A.J. Denomy (Eds.). Univ. of Wisconsin Press, Madison, Milwaukee, London, 1968, p. 538.

16 En El manual de los inquisidores de Nicolau Eimeric-Francisco Peña se dice que «Los sospechosos vehementes no deben considerarse herejes". Pero, seguimos dentro del tecnicismo, porque inmediatamente se plantea cómo hay que proceder con ellos, y establece que *Se les exigirá una abjuración de todas las herejías y en especial de las que se han hecho vehementemente sospechosos... El sospecho vehemente que se niegue a abjurar ante el juez inquisitorial será entregado al brazo secular para ser quemadow. Es una pena similar a la que establece para los sospechosos violentos, a los que «hay que considerar herejes*. EIMERIC-PEÑA 1996, p. 106. El texto original de Eimeric era de 1376, pero en 1578 se publicó la revisión y ampliación que la Santa Sede había encargado al canonista Francisco Peña. Hasta 1607 se reeditó tres veces en Roma y dos en Venecia. Ahora bien Finocchiaro cita el Sacro arsenale ovvero Prattica dell'officio della Santa Inquisizione, de 1621, y especifica que en este último se aclara que, en la práctica, el vehementemente sospechoso y el sospechoso violento son equivalentes. FinOCCHIARO 1989, pp. 14-15 y 326.

17 ALQUIÉ Ed. 1967, I, p. 492-493; ADAM-TANNERY (Eds.), t. I, p. 281; véase tambien Ibid. p. 288; y t. III, pp. 349-350; véase también GallLEO, Opere XV, p. 340-341.

18 Galileo, Opere v, p. 342.

19 Naturalmente, el Papa había participado en todo el proceso, como dejan bien claro los documentos.

20 Gallieo, Opere XII, p. 244. Recuérdese cómo los teólogos de la Inquisición afirman en su informe que la teoría copernicana es *formalmente herética, puesto que (quatenus) contradice explícitamente numerosas afirmaciones de las Sagradas Escrituras*, es decir, identifican «formalmente herético* y *contradictorio con las escrituras». Véase más arriba, nota 15.

21 Carta de Galileo a Pichena del 12 de marzo de 1616, Opere XII, p. 248.

22 ALQUIÉ Ed. 1967 I, p. 495.

23 Galileo, Opere V, p. 320.

24 Ricciol, Almagestum Novum, Bononiae 1651, t. I, par. II, p. 486. Citado por D'ADDIO 1992, p. 211.

25 Así lo hacen D'ADDio 1993, pp. 209-210, y BRANDMULler en BRANDMÚllerGreipl (Eds.) 1992, p. 24. Con todo, en los casos de Mersenne, Gassendi o Pascal, mas próximós a un kescepticismo mitigado», habría que hacer otras matizaciones.

26 Riccioli citaba a Honoré Fabri, también jesuita y miembro de la Inquisición, en apoyo de esta tesis. BrandMULler (BRANDMULLER-Greipl (Eds.) 1992, p. 28), y 


\section{«Una reflexión serena y objetiva». Galileo y el...}

también D'ADDIO 1992, pp. 211-212, recuerdan que, en su discusión con Huygens, Fabri llegó a aceptar que si se encontrara una prueba del movimiento terrestre, podría acomodarse al sentido de la Escritura y el geocentrismo sería abandonado. Pero ninguno de los dos menciona el hecho de que por ello, en 1671, Fabri fue condenado por la Inquisición romana a cincuenta dias de prisión. Véase SEgRE 1991, p. 141.

27 BRANDMULLER-GREIPL (Eds.) 1992, p. 26.

28 Véase BALdini 1992, Parte I, esp. pp. 76-119. Me permito remitir para un cierto desarrollo de esta cuestión a A. BELTRÁn 1994, pp. XVI-XXV, esp. XX y ss.

29 La carta de PEIRESC a GASSENDI, del 6 de Septiembre de 1633, dice así: «El buen padre, [Kircher] al que vimos cuando estaba de paso por aquí, no pudo por menos de confesarnos, en presencia del padre Ferrand, que el padre Malapert y el propio Clavius no desaprobaban la opinión de Copérnico e incluso que no estaban muy lejos de ésta, pero que habían sido empujados y constreñidos a escribir en favor de la común doctrina aristotélica, que el propio padre Scheiner apoyaba únicamente por orden y obediencia". (GALILEO Opere XV, p. 254) Y el propio Scheiner, que estaba escribiendo una obra antigalileana, su Prodomus pro sole mobile et terra stabile, había escrito a Kircher dos meses antes, diciéndole: "Cuando el Prodomus esté terminado, con la ayuda de Dios defenderé la astronomía común contra Galileo, a lo largo de todo el libro, como ha sido recomendado por el Papa, nuestro General y los Asistentes, todo en pro de cosas más importantes". (Galileo Opere XV, p. 184; cursiva mía) Y Descartes, en su carta citada más arriba, de febrero de 1634, comenta que ha oído decir que los jesuitas han colaborado en la condena de Galileo, y recuerda el encono que la obra de Scheiner Rosa Ursina, muestra hacia Galileo. Entonces añade: "Pero, por otra parte, las observaciones que hay en este libro proporcionan tantas pruebas para quitar al Sol los movimientos que se le atribuyen, que no puedo creer que el propio padre Scheiner en el fondo no crea la opinión de Copérnico». AlQUí́ Ed. 1967, I, p. 492-493.

30 Véase Ugo Baldini 1992, cap. VI, pp. 217-251, esp. 221 y ss.

31 Citado por D'AdDio 1993, p. 212.

32 BRANDMÚlLER-GREIPL 1992, p. 30

33 Idem.

34 BRANDMULLER-GREIPL 1992, p. 34.

35 Resulta sorprendente la coincidencia de que tres de los estudiosos pertenecientes comisión nombrada por el papa en 1980 para aclarar sin partidismos el caso Galileo incurran en el mismo error, en dos de los "estudios históricos" que le sirvieron al Papa para dar por zanjado el asunto. Costabel (en POUIARD 1984, p. 198) afirma que la obra de Copérnico fue retirada en 1757 y las de Galileo en 1822. Por su parte, el pronuncio apostólico en Burundi, Bernard Jacqueline afirma que en 1757 se retiró la "lista de libros que enseñaban la movilidad de la Tierra y la inmovilidad del Sol». Y en un rizar el rizo afirma que, por tanto, "los libros de Galileo no siguieron en el Indice hasta 1818, como cree el profesor A.R. HaLl" (en Poupard 1984, p. 192-193). D'Addio, por su parte, también afirma que, en 1757 , se retiraron del Indice "todos los libros que sostenían la teoría copernicana". D'Addio 1993, p. 216-217. Y todos ellos sacan conclusiones parecidas a la de Brandmüller que cito a continuación. Véase sobre este punto FANTOLI 1997, pp. 462 y 481-482.

36 Ibid. p. 35.

37 D'AdDIO 1993, pp. 219-220.

38 Tanto con la publicación de su Teoria de la Tierra de 1749 , como con la de su obra Las épocas de la naturaleza, de 1778, Buffon fue censurado porque sus teorías 
de la formación de la Tierra no se compadecía con las Sagradas Escrituras. Pero todo quedó en una mascarada acordada entre los censores y Buffon. Cuando parecía que Las épocas... iba a ser denunciada, Buffon le comentaba a un Guéneau de Montbeillard en una carta de 30 de agosto de 1779 amigo "no creo que este asunto tenga otras consecuencias molestas que la de oir hablar y tener que ocuparme quizás de una explicación tan tonta y absurda como la primera que se me hizo firmar hace treinta años». Y años mas tarde le comentaba a Hérault de Séchelles «Cuando la Sorbona me metí en líos no tuve ninguna dificultad en darles todas las satisfacciones que pudieran desear. No era más que una tomadura de pelo, pero los hombres son bastante tontos para contentarse con ellow. Para esta cuestión y las referencias completas puede verse A. BELTRAN. "La historia natural de Buffon: la eternidad en la historia", Introduccion a Buffon. Las épocas de la naturaleza. Alianza Ed. Madrid 1997, pp. 79-80, y 118.

39 Alocución de Juan Pablo II a un grupo de premios Nobel, el 22 de diciembre de 1980. Véase Gargantini 1985, p. 145.

40 D'ADDIO 1993, p. 220-221.

41 G. TIRABoschi, Storia della letteratura italiana. Milano 1833, IV, p. 438. Citado por D'ADDIo 1993, p. 222. Véase también BRANDMƯlleR-GREIPL (Eds.) 1992, pp. 41-44.

42 BRANDMULLER-GReipl (Eds.) 1992, p. 45.

43 Morpurgo-Tagliabue 1963, p. 52. Puede verse también al respecto la interpretación de BALDINI 1992, pp. 292 y 319. $1992^{2}$.

44 Esto es especialmente destacado en su Galileo y la Iglesia, BRANDMÚller,

45 En su Diario, Settele deja clara cuál es su opinion respecto a los protagonistas del asunto y sus tácticas: «En definitiva, se ve que todos son cortesanos, y niegan la verdad conocida para no chocar con las personas que desempeñan cargos.... Y más adelante, tras oir los argumentos *téricos* que planeaba utilizar Olivieri (los veremos a continuación), comenta Settele: «Son bonitas sofisterias, y de calidad; el padre Olivieri está convencidísimo del movimiento de la Tierra, pero es fraile, además dominico, y afecto a la Inquisición, y todo esto basta para desarreglarle la cabezaw. MAFFEI 1987, pp. 290 y 293.

46 BRANDMUlleR-GReipl (Eds.) 1992, pp. 293. Grandi explicita a su vez: «Honrado por sus excelencias reverendísismas con la delicada misión de proponer un expediente que salve el decoro de la Santa Sede sobre el asunto de la publicación de los Elementos de Astronomía del sr. canónigo Settele, procuraré hacerlo con la mayor brevedad posible, sometiendo mi parecer a sus excelencias reverendísimas*. BRANDMULLER-GREIPL 1992, pp. 293 y 294 .

47 BRANDMULLER-GREIPL (Eds.) 1992, p. 294.

48 Diario de Settele, 23 de octubre de 1820 . MafFeI 1987, p. 368.

49 Diario de Settele, 17 de diciembre de 1820. MAFFE 1987, p. 380.

50 Diario de Settele, 20 de febrero de 1820 y 22 de diciembre de 1820. MAFFEI 1987 , pp. 295 y 381.

51 Diario de Settele, 17 de diciembre de 1820. MafFei 1987, p. 379.

52 Brandmuller-Greipl (Eds.) 1992, p. 483.

53 Diario de Settele, 21 de diciembre de 1820 . MAFFEI 1987, p. 380.

54 Diario de Settele, 27 de diciembre de 1820 . MAFFEI 1987, p. 383.

55 Diario de Settele, 23 diciembre de 1820 . MAFFEI 1987, p. 381.

56 Razones por las que el Maestro del Sacro Palazzo Apostólico ha creido y cree que no se puede permitir la publicación del manuscrito del señor canónigo Settele, 
que empieza "Moviendose la Tierra en Torno al Sol». BrandmUller-GreIPL (Eds.) 1992, pp. 336-349.

57 BRANDMULLER-GREIPL (Eds.) 1992, p. 336.

58 BRANDMULLER-GREIPL (Eds.) 1992, p. 338.

59 BRANDMULleR-GREIPL (Eds.) 1992, p. 339.

60 BRANDMULleR-GREIPL (Eds.) 1992, p. 340. Recuérdese lo dicho en nuestra nota 35 , a este respecto.

61 BRANDMULLER-GREIPL (Eds.) 1992, p. 343.

62 BRANDMULlER-GREIPL (Eds.) 1992, p. 344. Ante estos argumentos Brandmüller cree suficiente lamentarse: «No nos queda más que cabecear». Los califica de «completamente absurdos* y ridiculiza la idea de que la recta interpretación de la Escritura venga determinada *por la asistencia del Espíritu Santo* en lugar de *por los resultados de la investigación en el campo de las ciencias naturales». BRANDMULLER-GREIPL (Eds.) 1992, pp. 99-100. Creo que, aunque sea un poco irreverente, se le puede aceptar que lo de la intervención del Espíritu Santo es una tontería, pero está lejos de ser exacto que la interpretación que hace la Iglesia de los textos bíblicos venga «determinada* por los resultados de la investigación científica.

63 "Riflessioni di Maurizio Olivieri sopra $i$ "motivi" pe' quali il R.mo P. Filippo Anfossi dice di aver negato l" "imprimatur" alla publicazione di Giuseppe Settele", BRANDMULLER-GREIPL (Eds.) 1992, pp. 225-287. En otros dos textos, Ibidem, pp. 317-325 y 351-384 insiste en sus argumentos.

64 BRANDMUULLER-GREIPL (Eds.) 1992, pp. 318-319.

65 Veremos que se trata precisamente de lo que el padre Paschini llamará «el acostumbrado sofisma».

66 Pero si tomáramos en cuenta las «razones filos6ficas» que se adujeron en aquel contexto, el argumento no hace sino volverse en contra de Olivieri. Baste recordar que, en su carta a Foscarini, para afirmar la evidente falsedad del copernicanismo, Bellarmino aducía el sentido común y, en definitiva, la incompatibilidad con la física aristotélica. Es decir, que sus propuestas teóricas alternativas eran mucho más absurdas e irresolubles que los de Galileo. Por tanto, evidentemente, las teorías del 8. XIX son doblemente irrelevantes y el argumento de Olivieri no hace sino empeorar la actuación de los inquisidores del s. XVII. Pero cabe insistir en lo erróneo del argumento de Olivieri. U. Baldini, que desde luego no puede considerarse un crítico de Bellarmino, lo expone con claridad: «[Bellarmino] no entendió la defensa del geocentrismo como una defensa de la astronomía ptolemaica y ni siquiera, fundamentalmente, de la física aristotélica y de su síntesis escolástica en el pensamiento cristiano; la entendió esencialmente como defensa del valor de verdad de la Escritura, que consideraba pilar de la credibilidad del cristianismo, e identificaba con el valor de verdad de cada uno de sus enunciados*. BALDINI 1992, p. 322.

67 BRANDMÚlLER-GREIPL (Eds.) 1992, pp. 241-242.

68 Un momento especialmente brillante lo alcanza Olivieri cuando sitúa a Sto Tomás como precursor de Copérnico. A partir de la afirmación del aquinate según la cual, dada la muitiplicidad de hipótesis astronómicas ninguna es definitiva, y puede haber alguna otra que pudiera salvar las apariencias irregulares del movimiento planetario que aún no se le haya ocurrido a nadie. Olivieri infiere que todas las hipótesis que Sto. Tomas tenía en mente eran geocentristas y que al referirse a otra posibilidad, el santo "presintí e indicó con una especie de adivinación" el movimiento de traslación de la Tierra, anticipando así a Copérnico. BRANDMUller-Greipl (Eds.) 1992, p. 266. 
69 BrandMUller-Greipl (Eds.) 1992, p. 268.

70 BRANDMUt.LER-GREIPL (Eds. ) 1992, pp. 270-271. No puedo resistirme acitar la apostilla de Brandmüller: "Cuando Olivieri escribía esto, jciertamente no era consciente de no estar muy lejos del punto de partida de la teoría de la relatividad!» Ibid., p. 107. Estamos en plena orgía apologética.

71 BRANDMULLER-GREIPL (Eds.) 1992, p. 479.

72 "No ha de causar extrañeza, pues, si aquellos grandísimos hombres, que tenían sobre sus espaldas las carga de los miles de libros que están incluidos en el Indice, no cumplieron su labor con los libros concretos [los explícitamente prohibidos por copernicanos]. Si hubieran tenido ocasión y holgura para examinarlos todos, quien no dará por seguro que habrían reconocido como una consecuencia del permiso general, que se eliminaran del Indice las prohibiciones concretas, esto es la de Galileo, Zúñiga, Foscarini..." BRANDMULLER-GREIPL (Eds.) 1992, pp. 479-480.

73 BRANDMULLER-GREIPL (Eds.) 1992, p. 116.

74 BRANDMUller-Greipl (Eds.) 1992, pp. 129-130.

75 Nótese que esto está escrito antes de que ninguna de las secciones de la comisión encargada del caso Galileo hubiera presentado sus conclusiones, que curiosamente, como sabemos, llegaron a esta misma conclusión del Papa.

76 GaRgantini 1985, p. 134.

77 Discurso del Santo Padre a la Academia Pontificia de las Ciencias el sábado 31 de octubre de 1992, en BRANDMÚlLeR 1992, p. 197.

78 Idem.

79 SimONCELli 1992 , p. 16. Las dos frases son claramente contradictorias. Pero la posición de Gemelli estaba clara desde mucho antes. Un trabajo suyo de 1929, sobre Galileo, había sido comentado muy elocuentemente por Timpanaro: «El discurso del padre Agostino Gemelli sobre las relaciones entre ciencia y filosofía en la historia del pensamiento italiano. ¡Qué razonamiento tan melancólico! La verdad está toda, o casi toda, en Santo Tomás de Aquino; después, en Italia y fuera, no hay más que decadencia... «Galileo... aprendió a su pesar cuán ingenua era su concepción”. Esta interpretación de la tragedia de Galileo duele y asombra..." TimPANARO 1952, pp. 286-287. En la celebración del tercer centenario de la muerte de Galileo, Gemelli escribiría un artículo titulado "Scienza e fede nell uomo Galileo", en el que avanza lo que puede considerarse la posición oficial y ofrecía el contexto adecuado a Paschini. Tras los excesos ideológicos del XIX, decía Gemelli, "los católicos no temen reconocer lealmente que el proceso contra él fue un error". Frente a las interpretaciones ideológicas que le han presentado como símbolo del enfrentamiento entre la razón y la fe, "podemos hoy, con más serena visión, admitir que es un hombre que en el fondo de su alma ha realizado el acuerdo entre razón y Fe, entre ciencia y Religiónn. SimONCELLI 1992, pp. 46-47.

80 Simoncelli 1992 , p. 64.

81 Un documento que aún hoy no conocemos a pesar de que Juan Pablo II prometía en 1979 su "personal apoyo" a esa "profundización en el caso Galileo" que decía desear tanto.

82 SiMONCELLI 1992, p. 73.

83 SimonCELli 1992, p. 73. En una carta a Montini sohre al mismo documento de la Inquisición, Paschini nace un comentario que vale la pena citar. "De hecho, no me habría negado a temperar o modificar las expresiones que se desease que yo corrigiera e incluso lo habría hecho gustosamente. Pero las que se me han objetado 
las he escrito precisamente para distinguir claramente las responsabilidades de los consultores de 1633 de las de la Iglesia y de la propia Inquisición. No es culpa mía si éstos nos ofrecen una pobre imagen, que hoy es conocida de todos". SimONCELLI 1992, p. 72.

84 «Pero ciertamente -comenta Paschini- yo no podía, para agradar a quien estaba interesado, falsear los resultados de mi investigación. Es decir, no podía repetir lo hecho por el padre Müller con un libro ignominioso como el suyo; porque hay que tener el coraje de decir la verdad aunque ésta nos pueda resultar amarga». SimONCELLI 1992 , p. 77. Se refiere al libro del padre Adolfo Müller, Galileo Galilei. Studio storico-scientifico, traducido al italiano por el padre Perciballi, Roma, Tipografia Cuggiani, 1911 (orig. 1909) Dicho sea de paso, este texto es una de las autoridades favoritas de Brandmüller 1992. Pero hubo humillaciones peores. Paschini estaba muy lejos de las directrices historiográficas oficiales de la Iglesia, que criticó explícitamente. No obstante, aceptó, no sólo dirigir la Enciclopedia Cattolica, que encarnaba paradigmáticamente las directrices oficiales que tan duramente había criticado, sino que aceptó escribir la voz Galileo con un artículo que silenciaba los aspectos que habian planteado problemas en su vita di Galileo, citando además los trabajos de los censores y jueces que habían prohibido su libro, como Armellini o Gemelli.

85 MACCARRONE 1979, p. 212.

86 Nota Introductoria, p. XIII; citado por SimONCELLI 1992, p. 114.

87 MACCARRONE 1979 , p. 213.

88 BRANDMUller 1992, p. 18. Se trata de un libelo cuya escasa talla intelectual sólo se ve superada por su bajeza moral. No analiza un solo argumento de Galileo -ni de ningún otro-, ni cita directamente sus obras ni una sola vez. Sus grandes fuentes son, Adolf Müller, autor del estudio sobre Galileo que el propio Paschini calificó de «libro ignominioso»; el jesuita Filippo Soccorsi, que le hacía una dura competencia a Müller, y, naturalmente, la «versión manipulada* del libro de Paschini. Parece claro que, con este panfleto, hizo los méritos necesarios para ser elegido para cuidar la edicion de las actas de la Inquisicion relacionadas con el caso Settele (BRANNDMU. LLER-GREIPL (Eds.) 1992. Desde luego, Brandmüller posee las cualidades necesarias para conseguir hallar una «solución honorable* al caso Galileo, tal como pidió Juan Pablo II en 1979.

89 En la discusion de 1 de abril de 1965. MACCARRONE 1979, p. 216. Cabe recordar que Parente era el asesor del Santo Oficio que, en 1963, había manifestado sus reservas sobre "la utilidad del libro y la oportunidad de la publicación* de la obra de Paschini. Ahora, tras la manipulación, el mismo propone citarla en el Concilio.

90 Idem.

91 "Constitución sobre la Iglesia en el mundo actual». Concilio Vaticano II. Constituciones. Decretos, Declaraciones. B.A.C. Madrid, 1966, p. 257.

92 Poupard Ed. 1983, p. 274.

\section{Bibliografía}

Adam, Charles y Tannery, Paul, (Eds.) 1957-1958: Oeuvres de Descartes. Vrin, París. ALQUIÉ, Ferdinand (Ed.) 1967: Oeuvres philosophiques de Descartes. Garnier, París. 
BALdINI, Ugo, 1992: Legem impone subactis. Studi su filosofía e scienza dei gesuiti in Italia 1540-1632. Bulzoni Editore, Roma.

BELtrán, A., 1994: Véase Introducción a Galileo 1994.

Bertolla, Pietro, 1979: "Le vicende del "Galileo" di Paschini (dall-' Epistolario Paschini-Vale)", en Atti del Conveggno di Studio su Pio Paschini nel Centenario della Nascita 1878-1978. Publicazioni della Deputazione di Storia Patria per il Friuli, 10, pp. 173-208.

Brandmuller, Walter, 1992: Galileo y la Iglesia. Ediciones Rialp, Madrid, 2. ed. ampliada con el Discurso pronunciado por S.S. Juan Pablo II en día 31 de octubre de 1992 en la Pontificia Academia de las Ciencias, Trad. Elisabeth Wannieck, Ediciones Rialp, Madrid.

Brandmuller, Walter-Greipl, Egon J., (Eds.) 1992: Copernico, Galilei e la Chiesa. Fine della controversia (1820) Gli Atti del Sant'-Uffizio. Pontificia Academia Scientiarum. Leo Olschki Editore, Firenze.

Concilio Vaticano II. Constituciones. Decretos, Declaraciones. B.A.C. Madrid, 1966

D'ADDIo, Mario, 1993: Il caso Galilei. Processo/Scienza/Verità. Edizioni Studium, Roma. Constituye una edición ampliada de dos artículos "Considerazioni sui processi a Galileo", publicados en la Rivista di Storia della Chiesa in Italia en 1983 y 1984.

EIMERIC, Nicolau y PENAA, Francisco, 1996: El manual de los inquisidores. Atajos, Muchnik-Editores S.A. (orig. 1578).

FANTOLI, Annibale, 1997: Galileo, per il copernicanesimo e per la Chiesa, Studi Galileiani vol. 2, Specola Vaticana, Libreria Editrice Vaticana, Città del Vaticano, Seconda edizioni riveduta e corretta.

Finocchiaro, Maurice A., 1989: The Galileo Affair. A Documentary History. Univ. of California Press, Berkeley, Los Angeles, London.

Galileo Galilei, 1968: Le Opere di Galileo Galilei. Edizione Nazionale, A. cura di A. Favaro, 20 vols, G. Barbèra, Firenze, (1 $1^{\text {a }}$ ed. 1890-1909).

- 1994: Diálogo sobre los dos máximos sistemas del mundo ptolemaico y copernicano. Introducción, traducción, notas e índices Antonio Beltrán. Alianza Ed., Madrid.

Gargantini, Mario, 1985: I Papi e la Scienza. Antologia del Magisterio della Chiesa sulle Questioni Scientifiche da Leone XIII a Giovanni Paolo II. Jaca Book, Milano.

MACCARRONE, Michele, 1979: "Mons. Paschini e la Roma ecclesiastica», in Lateranum, XLV, 1979, pp. 158-218.

MAFFeI, Paolo, 1987: Giuseppe Settele, il suo Diario e la Questione Galileiana. Edizioni dell'Arquata, Foligno.

Morpurgo-TAgliabue, G., 1963: I processi di Galileo e l'epistemologia. Edizioni di Comunità, Milano.

Pagano, Sergio M., 1984: I documenti del processo di Galileo Galilei. Pontificiae Academiae Scientiarum Scripta Varia, 53, Citta del Vaticano, Archivio Vaticano.

Poupard, Paul Mnr. (Edr.) 1983: Galileo Galilei. 350 Ans d' Histoire 1633-1983. Desclée International, Tournai.

Redond, Pietro. 1990: Galileo herético. Trad. de Antonio Beltrán. Alianza Ed, Madrid. (orig. 1983).

SEGRE, Michael, 1991: In the wake of Galileo. Rutgers University Press, New Brunswick, New Jersey.

Simonceldi, Paolo, 1992: Storia di una Censura. "Vita di Galileo» e Concilio Vaticano II. Franco Angeli, Milano.

Timpanaro, Seb., 1952: Scritti di Storia della Scienza. Sansoni, Firenze. 